\title{
INTERNATIONAL TRADE AND BUSINESS CYCLES
}

Marianne Baxter

Working Paper No. 5025

\section{NATIONAL BUREAU OF ECONOMIC RESEARCH 1050 Massachusetts Avenue Cambridge, MA 02138 \\ February 1995}

I would like to thank, without implicating, the following individuals who have provided very helpful comments and suggestions: David Backus, Mario Crucini, Atish Ghosh, Urban Jermann, Patrick Kehoe, Robert King, Michael Kouparitsas, Maurice Obstfeld, Kenneth Rogoff, Kei-Mu Yi, and Alex Wolman. This paper is part of NBER's research programs in International Finance and Macroeconomics and Economic Fluctuations. Any opinions expressed are those of the author and not those of the National Bureau of Economic Research.

(C) 1995 by Marianne Baxter. All rights reserved. Short sections of text, not to exceed two paragraphs, may be quoted without explicit permission provided that full credit, including (C) notice, is given to the source. 


\title{
INTERNATIONAL TRADE AND \\ BUSINESS CYCLES
}

\begin{abstract}
Virtually all economies experience recurrent fluctuations in economic activity that persist for periods of several quarters to several years. Further, there is a definite tendency for the business cycles of developed countries to move together--there is a world component to business cycles. This paper argues that capital accumulation and international capital flows are central to understanding world trade and business cycles. In particular, fluctuations in net exports and the current account are shown to be dominated by trade in capital goods. The paper develops a two country model of international trade within which capital accumulation and international investment flows play a central role. We explore the channels by which technology shocks and fiscal shocks are transmitted to the domestic and foreign economies, and discuss the extent to which these results are sensitive to individuals' opportunities for international trade in financial assets. Overall, we find that the models capture many of the salient features of international business cycles. However, it has proven consistently difficult to generate sufficient comovement across countries in labor input and investment. The paper concludes with a discussion of fruitful directions for future research.
\end{abstract}

\author{
Marianne Baxter \\ Department of Economics \\ Rouss Hall \\ University of Virginia \\ Charlottesville, VA 22903-3288 \\ and NBER
}




\section{Introduction}

Virtually all economies experience recurrent fluctuations in economic activity that persist for periods of several quarters to several years. Further, there is a definite tendency for the business cycles of developed countries to move together-there is a world component to business cycles. The challenge to theory is to develop a consistent explanation for these phenomena. This chapter summarizes the contributions of a particular branch of the literature on open economy macroeconomics. This research has stressed the importance of general equilibrium considerations for understanding business cycles - even in small economies. Further, this research program has stressed the importance of modeling the dynamics of capital accumulation together with the consumption/saving/labor supply decisions of individuals. As we shall see, there have been some notable early successes of this approach, yet much work remains to be done. Thus, the goals of this chapter are threefold. First, we review the empirical motivation for this approach and evaluate the successes and failures of the early models in capturing the main features of international business cycles. Second, we explore in detail the predictions of this approach for the business-cycle response of home and foreign economies to shocks to domestic fiscal variables and to technology. Third, we describe current research which extends the basic model in several directions, and outline some directions for future research.

This chapter is structured as follows. Section 2 investigates the empirical determinants of the current account, and finds that flows of durable goods are an important determinant of current account movements. In particular, since investment is a highly volatile macroeconomic aggregate, movements in investment play a dominant role in fluctuations in the current account at business-cycle frequencies. Section 3 presents the basic two-country model. This is a general equilibrium model of two countries producing a single consumption-investment good, with frictionless trade in goods. Despite the model's simplicity, it contains the three most important elements for thinking about the determinants of business cycles and the current account in general equilibrium: intertemporal optimization by consumers, optimal investment decisions by producers, and endogenous determination of the interest rate. This section also discusses alternative assumptions regarding the degree of market completeness, and specifies how the model may be closed under each set of assumptions. Section 4 addresses the issues associated with solving and simulating dynamic equilibrium models. This section also discusses the literature on the measurement of productivity.

Section 5 studies the business cycle and current account dynamics in the basic model, when the economy is subject to stochastic disturbances to total factor productivity. The key finding is that asset market restrictions are more likely to be important (i) the more persistent is the shock; and (ii) the less rapidly the shock is transmitted abroad. When there are important differences across asset structures, 
these stem from differences in the wealth effects, and not from differences in substitutions associated with variations in interest rates and wage rates. Section 6 studies the business-cycle implications of the one-good model. The main finding here is that the basic model does an adequate job of replicating many of the main features of within-country business cycles, but three main puzzles remain. This section also explores the relationship between country size and the volatility of the current account and national business cycles.

In section 7 , we study the effects of shocks to government spending and tax rates. We examine how the effects of a fiscal shock depends on the source of the shock and its expected duration, and use our model to discuss the link between fiscal deficits and interest rates, and also investigate its predictions for the "twin deficits" phenomenon.

Section 8 reviews the literature on multi-good models of international business cycle. We begin by reviewing the recent literature on the "J-curve;" we then discuss the extent to which the multi-good model overcomes the problems inherent in the onegood model, and conclude with a discussion of related literature. Section 9 concludes with a brief summary and a discussion of potential directions for future research.

\section{Business cycles and the current account in open economies}

This section reviews the salient features of international business cycles and current account fluctuations. These features of the data will guide the quantitative theory which is the subject of the remainder of the chapter.

\section{$2.1 \quad$ Filtering issues}

Since many macroeconomic time series are nonstationary, computation of moments requires that the data be transformed to remove the nonstationarity. A commonly used transformation is the linear filter advocated by Hodrick and Prescott (1980). ${ }^{1}$ The important properties of this filter are the following: (i) the filter will render stationary any time series that is integrated of order four or less; and (ii) when applied to quarterly data, the filter acts as a reasonable approximation to a high-pass filter that passes cycles of frequency eight years or less with the customary value of $\lambda=1600$ for the smoothing parameter. Alternative approaches to filtering are application of the first-difference filter, and removal of deterministic trends.

Recently, Baxter and King (1994) proposed a method for measuring business cycle components of models and data through the application of an approximate band-pass filter. The basic idea is to follow Burns and Mitchell (1946) and current NBER practice in defining a 'business cycle' as those components of the data with

\footnotetext{
${ }^{1}$ The properties of this filter have been extensively studied: see, for example, King and Rebelo (1993).
} 
periodicity between six and thirty-two quarters. For quarterly data, the approximate band-pass filter and the Hodrick-Prescott filter generally yield similar results. ${ }^{2}$

\subsection{Open economy business cycles}

A large and growing literature on the statistical properties of international business cycles finds that fluctuations across countries and across time periods display a remarkable consistency in the key stylized facts. ${ }^{3}$ Within countries, consumption and investment tend to be strongly procyclical, with consumption less volatile than output and investment more volatile. Net exports are countercyclical. Across countries, cyclic movements in output tend to be positively correlated, as are cyclic movements in consumption, investment, and labor input. Table 1 details the key business-cycle statistics for ten industrialized countries. We present results for the following macroeconomic aggregates: real output, real consumption purchases (including durables), real investment, employment, government purchases, and net exports as a fraction of output. $^{4}$

\subsubsection{Within-country business cycles}

The first panel of Table 1 presents volatility statistics, defined as the standard deviation of each aggregate, measured as per cent per quarter (except for net exports); panel $B$ reports the volatility (standard deviation) of the macro aggregates relative to own-country output. The volatility of output ranges between about one and two percent, while consumption is generally slightly less volatile than output, with investment being about two to three times more volatile than output. The relative volatility of employment ranges from a low of about .35 (Italy and Japan) to a high of 1.31 in Austria. Government purchases of goods and services also display a wide range of relative variation, as do net exports. With regard to net exports, the U.S. is the outlier (0.25). In the other countries considered, net exports are substantially more

\footnotetext{
${ }^{2}$ At other data frequencies, the correspondence between the Hodrick-Prescott filter and the business-cycle filter will not be close, unless the researcher correctly sets the value of the HodrickPrescott "smoothing parameter," commonly denoted $\lambda$. With annual data, for example, current practice is to set $\lambda=100$ or $\lambda=400$. However, the value of $\lambda$ required to approximate the businesscycle filter in annual data is $\lambda=10$. Higher values of $\lambda$ pass through too much of the low-frequency variation in a series, compared with the ideal filter; see Baxter and King (1994) for more details.

${ }^{3}$ Several papers in the literature compare business cycles across countries; see for example, papers by Backus, Kehoe, and Kydland (1992a,b), and Blackburn and Ravn (1991). There is also a growing literature on business-cycle stylized facts within specific countries: see, for example, Blackburn and Ravn (1992), Brandner and Neusser (1992), Correia, Neves, and Rebelo (1992), Englund, Persson, and Svensson (1990), and Kim, Buckle, and Hall (1992).

${ }^{4}$ The data are originally from the OECD and the IMF, and were assembled and provided by David Backus, Patrick Kehoe, and Finn Kydland. The time period covered is 1970-1990. The logarithms of all variables (except net exports, which is left in level form) were filtered with the $B P_{12}(6,32)$ filter defined by Baxter and King (1994).
} 
volatile relative to output, with relative volatility statistics in the range 0.50 to 0.90 . Panel $\mathrm{C}$ of Table 1 summarizes the patterns of within-country comovement at business cycle frequencies. Consumption, investment, and employment are all strongly procyclical. Government purchases, by contrast, appear largely acyclic. Finally, net exports are uniformly countercyclical.

\subsubsection{Cross-country business cycles}

Panel D of Table 1 shows the pattern of international comovement in macro aggregates. Specifically, this table gives the correlation of each macro aggregate with the corresponding U.S. aggregate. Here we observe the tendency for outputs of developed countries to move together: the correlation of every country's output with that of the U.S. is positive and in fact is quite substantial for several of the countries. Consumption also tends to be positively correlated across countries, but here the correlations are smaller. In fact, there is no country in our sample for which the consumption correlation exceeds the output correlation. Investment also tends to be positively correlated across countries, as do employment and government purchases. Net exports, by contrast, exhibit much lower correlation across countries, with most countries showing a negative correlation between their net exports and those of the United States. (As a group, of course, the rest of the world must have net exports that are negatively correlated with those of the U.S.)

\subsection{The current account}

The current account-defined as the difference between national saving and national investment - is heavily scrutinized by policymakers and economists alike as an important barometer of a country's health. Because a current account deficit corresponds to domestic dissaving (or accumulation of debt), news of these deficits is typically received with alarm. Since the current account occupies such a prominent position in policy debates, we devote this sub-section to exploring the important empirical determinants of fluctuations in the net exports and the current account.

\subsubsection{Cyclic fluctuations in net exports and the current account}

For several reasons, it is useful to consider decomposing fluctuations in the current account into trend and business-cycle components. First, the models developed in the rest of this chapter focus primarily on the business-cycle fluctuations in the current account and macroeconomic activity. Second, to the extent that movements in the current account diverge from movements in net exports, these are likely to be due to divergences in interest payments on the national debt, which change slowly over time. In the U.S., for example, the stock of national debt is large relative to the quarterto-quarter changes in the stock. Thus the aggregate debt stock changes slowly, so that the difference between net exports and the current account also changes slowly, 
unless interest rates are exceptionally volatile. That is: the difference between net exports and the current account is concentrated in the low-frequency components of these time series.

To see this effect graphically, Figure 1 plots net exports and the current account for the U.S., together with the cyclic fluctuations in these variables, where the cyclic components are extracted using the $B P_{12}(6,32)$ filter. Although the levels of net exports and the current account can (and do) diverge from each other for sustained periods of time, their business-cycle components covary quite strongly. In fact, there is a strong correspondence between the business cycle fluctuations in the trade and current accounts for most countries, even during the period of high and volatile interest rates that occurred in the late 1970's-early 1980's (detailed results are not reported here due to space constraints).

\subsubsection{Components of the current account}

The share of durable goods in U.S. net exports has averaged about 50-60\% over the past 30 years. While durable goods account for a large fraction of international trade, they are even more important in terms of fluctuations in the trade and current account balances. The economic mechanism is easy to understand-investment is a volatile time series, thus international flows of investment goods are likely to dominate fluctuations in the trade account. The top two panels of Figure 2 plots real exports and imports for the U.S. together with their durable goods and capital goods components. The lower panels plot the cyclic components of these variables. This figure shows strikingly that the cyclic fluctuations in both exports and imports are almost exclusively due to fluctuations in durable goods. In fact, the fluctuations in durable goods trade are primarily the result of fluctuations in just one category of durable goods - the category labeled "capital goods." 5

\subsubsection{The current account and investment}

The summary statistics presented in Table 1 suggested a negative correlation between the level of national investment and the surplus on the current account or net exports, i.e., investment is positively correlated with output, while net exports are negatively correlated with output. This correlation is, in fact, negative for each of the countries studied, with the exception of Japan (these statistics are not reported in the table). The relationship between the current account and investment has also been the subject of regression analyses. In an early contribution, Sachs (1981) regressed the current account ratio on the GNP gap and the investment ratio for 14 countries, and

\footnotetext{
${ }^{5}$ This category includes aircraft, ships, tanks, engines, construction and mining equipment, a variety of types of industrial machinery, computer and office equipment, refrigeration and heating equipment, electrical equipment, and railroad equipment. Burda and Gerlach (1992) have emphasized the importance of durable goods for recent fluctuations in the U.S. trade balance; see also related work by Sadka and Yi (1994).
} 
found that current account deficits were associated with investment booms, and that this effect was stronger for smaller countries. More recently, Glick and Rogoff (1994) have found that investment booms were associated with current account deficits. ${ }^{6}$

Overall, on the basis of this look at the data, we have an emerging picture of the economic factors that are important for open economy business cycles and fluctuations in net exports and the current account. At the center of the picture are investment dynamics - the high volatility of investment is a central feature of national business cycles, and there is strong evidence that investment booms tend to be accompanied by a deficit in the current account. These factors have played a major role in the development of equilibrium models of international business cycles.

\section{The basic model}

This section develops a two-country version of the standard one-sector stochastic growth model. There is a single final good produced in each of the two countries: this good is used both for consumption and for investment. In this single-good model, international trade takes place both to smooth consumption and to equalize the crosscountry after-tax returns to capital. Despite the model's simplicity, it contains the three most important elements for thinking about the determinants of the trade and current accounts in general equilibrium: intertemporal optimization by consumers, optimal investment decisions by producers, and endogenous determination of the interest rate. These elements form the basis for the general principles that determine the economy's responses to shocks; these principles are discussed in detail below.

The world comprises two countries: the home country and the foreign country. This model is described by the equations below. ${ }^{7}$ The foreign country is distinguished from the home country by means of a star. Where stars are absent from foreigncountry equations, the variable, parameter, or function in question is assumed to be identical across countries. The model is discussed in terms of the home country alone when there is no danger of confusion; all variables are expressed in per capita terms unless otherwise stated.

\subsection{Preferences}

Residents of each country value leisure and consumption of the single produced good; labor is immobile across countries. Specifically, consumers in each country choose leisure $L_{t}$, and consumption, $C_{t}$, to maximize

\footnotetext{
${ }^{6}$ However, Penati and Dooley (1984) and Tesar (1991) have shown that this relationship may not be robust over all countries and all time periods.

${ }^{7}$ This presentation of the basic model draws on material in Rebelo (1987), Baxter and Crucini (1993a,b), and Crucini (1993a).
} 


$$
\begin{gathered}
E \sum_{t=0}^{\infty} \beta^{t} U\left(C_{t}, L_{t}\right) ; \text { home country; } \\
E \sum_{t=0}^{\infty} \beta^{t} U\left(C_{t}^{*}, L_{t}^{*}\right) ; \text { foreign country. }
\end{gathered}
$$

The period utility function, $U$, is specialized to a constant-relative-risk-aversion form, so that trend growth in wages does not lead to trend growth in leisure (see the discussion in King, Plosser, and Rebelo (1988) and also Principle \#5 below):

$$
U\left(C_{t}, L_{t}\right)=(1-\sigma)^{-1}\left(C_{t}^{\theta} L_{t}^{1-\theta}\right)^{1-\sigma}
$$

For the purpose of our analysis, we further specialize period utility by setting $\sigma=1$, so that we are in the familiar case of logarithmic utility: ${ }^{8}$

$$
U\left(C_{t}, L_{t}\right)=\theta \ln C_{t}+(1-\theta) \ln L_{t} .
$$

This specification of utility implies that consumption and leisure choice will be governed by five main principles, as follows.

PRINCIPLE \#1: Holding fixed the level of labor input, wealth is the primary determinant of the level of consumption.

PrincIPle \#2: Holding fixed the level of labor input, consumption growth is determined by the real interest rate. That is,

$$
\log \frac{c_{t+1}}{c_{t}}=\frac{1}{\sigma}\left(r_{t}-\bar{r}\right)
$$

where $\left(r_{t}-\bar{r}\right)$ denotes the deviation of the interest rate from its steady state level.

These first two principles are important for the consumption-savings decisions by households, and are exploited repeatedly by Obstfeld and Rogoff (this volume) in their analysis of the current account. In the presence of variable labor, there are three additional principles, the first two of which parallel those for consumption above:

PRINCIPLE \#3: Wealth is an important determinant of the level of leisure, i.e., it is an important determinant of labor supply.

PRINCIPLE \#4: Labor is intertemporally reallocated in response to changes in interest rates.

PRINCIPLE \#5: The real wage, and expectations concerning its future path, are important determinants of the level of labor supply. In particular, with the CRRA specification of utility, there is no labor supply response to a permanent increase in the level of the real wage. However, there are important labor supply responses to

\footnotetext{
${ }^{8}$ We adopt the log specification for period utility because it simplifies some aspects of our analysis. Much of the literature uses the specification (1) with $1<\sigma<5$. This alteration of preferences is not quantitatively important for the analysis of this paper.
} 
temporary changes in the real wage rate, since temporary changes in the wage rate induce intertemporal substitution.

Finally, individuals face the constraint that time devoted to market work plus leisure cannot exceed the time endowment, normalized to one unit in each country:

$$
\begin{gathered}
1-L_{t}-N_{t} \geq 0 ; \text { home country } \\
1-L_{t}^{*}-N_{t}^{*} \geq 0 ; \text { foreign country . }
\end{gathered}
$$

\subsection{Technology}

There is a representative firm operating in each country, whose goal is to maximize the present discounted value of cash flow. For the home country firm, the goal is to maximize $\sum_{t=0}^{\infty} P_{t}^{d} d_{t}$, where $d_{t}$ is the firm's cash flow in period t, and $P_{t}^{d}$ is the discount factor applied to cash flows in period $t$ (there is an analogous expression for the foreign firm). The home firm's cash flow is given by

$$
d_{t} \equiv Y_{t}-I_{t}-w_{t} N_{t}
$$

where $Y_{t}$ denotes gross output, $I_{t}$ is investment, $N_{t}$ is labor input, and $w_{t}$ is the real wage. Output in each country is produced via constant-returns-to-scale production functions. Production is subject to exogenous shocks to total factor productivity, which may be partly country-specific in origin:

$$
\begin{gathered}
Y_{t}=F_{t}\left(K_{t}, N_{t}\right)=A_{t} K_{t}^{1-\alpha}\left(X_{t} N_{t}\right)^{\alpha} ; \text { home country } \\
Y_{t}^{*}=F_{t}\left(K_{t}^{*}, N_{t}^{*}\right)=A_{t}^{*}\left(K_{t}^{*}\right)^{1-\alpha^{*}}\left(X_{t}^{*} N_{t}^{*}\right)^{\alpha^{*}} ; \text { foreign country, }
\end{gathered}
$$

where $K_{t}$ and $K_{t}^{*}$ denote the capital stocks utilized by the home and foreign firms, respectively. In general, $K_{t}$ does not correspond to capital owned by residents of the home country since individuals may be permitted to rent capital to firms in either country; similarly, $K_{t}^{*}$ does not necessarily correspond to foreign-owned capital. The variables $X_{t}$ and $X_{t}^{*}$ represent labor-augmenting technical change, and are assumed to grow at the common, constant (gross) rate $\gamma_{X} . A_{t}$ and $A_{t}^{*}$ are the stochastic components of the productivity variables.

Capital accumulates over time according to

$$
\begin{gathered}
K_{t+1}=(1-\delta) K_{t}+\phi\left(I_{t} / K_{t}\right) K_{t} ; \text { home country } \\
K_{t+1}^{*}=(1-\delta) K_{t}^{*}+\phi\left(I_{t}^{*} / K_{t}^{*}\right) K_{t}^{*} ; \text { foreign country }
\end{gathered}
$$

where $\delta$ is the depreciation rate of capital, and the function $\phi$ controls the number of units of output which must be foregone to increase the capital stock in a particular 
location by one unit, as in Hayashi (1982). We assume that $\phi>0, \phi^{\prime}>0$, and $\phi^{\prime \prime}<0$. Capital adjustment costs have been incorporated to mitigate the response of investment to location-specific shocks. With a single good produced in each of two countries, capital owners have a strong incentive to shift the location of their capital in response to persistent movements in productivity. Without some friction in the capital adjustment process, the model would display excessive volatility of investment.

In parallel with the principles governing the consumption and labor responses to shocks, there are several principles stemming from this specification of technology.

PrincIPLE \#6: The magnitude of the (worldwide) wealth effect on consumption and labor increases with the persistence of the shocks to wage and non-wage income. For a shock of given size - for example, a positive productivity shock in one countrythe magnitude of the wealth effect will be larger, the more protracted is the positive shift in productivity. The way in which this wealth effect is shared internationally will depend on the market structure, as discussed below.

Principle \#7: Labor demand by firms depends positively on the level of the capital stock and on the level of productivity. As we shall see in section 5 below, there are important dynamic interactions of labor and capital in response to shocks.

Principle \#8: Investment depends positively on Tobin's ' $q$ '一the value of existing capital relative to new capital. Tobin's ' $q$ ', in turn, depends positively on the marginal product of capital, which increases with labor input and the level of technology, and decreases with the level of the capital stock. Finally, Tobin's ' $q$ ' (and thus investment) depends negatively on the real interest rate. The response of investment to each of these variables is larger, in absolute value, the more persistent is the expected deviation from steady state levels.

\subsection{Government}

We assume that the government of the home country taxes national output at the rate $\tau_{t}$ (yielding tax revenues of $\tau_{t} Y_{t}$ ), purchases and disposes of goods in the amount $G_{t}$, and transfers goods to private individuals in the amount $T_{t}$. In the foreign country, the tax rate is $\tau_{t}^{*}$, government purchases are denoted $G_{t}^{*}$, and transfers are $T_{t}^{*}$. In both countries, variations in tax revenues stemming from variations in national outputs are offset either through variations in transfer payments, or through issuance of debt that will be repaid by increases in lump-sum taxes (decreases in transfers). Thus the flow budget constraints for the two governments are:

$$
\begin{gathered}
G_{t}+T_{t}=\tau_{t} Y_{t} ; \text { home country } \\
G_{t}^{*}+T_{t}^{*}=\tau_{t}^{*} Y_{t}^{*} ; \text { foreign country. }
\end{gathered}
$$

Ricardian equivalence obtains in this economy because of the infinite horizon of the representative individuals. That is: there is an equivalence between financing 
current government expenditures with lump-sum taxes, or financing them with debt which will be retired in the future by increasing lump-sum taxes. In section 7 below, we explore the model's implications for the domestic and international effects of disturbances to government purchases and tax rates.

\subsection{Market structure}

To close the model, we must specify the structure of markets available to individuals. We assume that there is frictionless international trade in output, so that there is a unified world resource constraint for the single produced good:

$$
\pi\left(Y_{t}-C_{t}-I_{t}-G_{t}\right)+(1-\pi)\left(Y_{t}^{*}-C_{t}^{*}-I_{t}^{*}-G_{t}^{*}\right) \geq 0 .
$$

In addition to the market for final goods, nations are also linked by financial markets. Since there is cross-country heterogeneity in the shocks to productivity, government expenditure and taxation, the extent of international financial linkages is likely to be important for the extent of consumption-smoothing and risk-pooling that individuals can achieve. By consumption smoothing, we mean the simple transfer of a unit of the consumption good from one date to another. By risk-pooling, we mean the transfer of consumption from one state of nature to another.

For the most part, the general equilibrium, open economy business cycle literature has studied models in which asset markets are assumed to be complete: individuals may trade any contingent claims they wish (see, for example, Backus, Kehoe, and Kydland (1992a) and Baxter and Crucini (1993a)). In equilibrium, individuals attain the optimal degree of consumption smoothing, and pool all idiosyncratic risks. By contrast, the small open economy literature (see, for example, Cardia (1991), Mendoza (1991), and Correia, Neves, and Rebelo (1994)) as well as the "intertemporal approach to the current account" (as exposited, for example, by Frenkel and Razin (1987)) typically assume that the only financial asset available to individuals is a risk-free real bond. That is: individuals can engage in consumption-smoothing, but not riskpooling.

Below, we investigate the extent to which financial linkages are likely to be important for business cycles and the behavior of the current account. At this point, we simply set up some additional notation necessary for discussing the economy in which financial trade is limited to a non-contingent real bond. For simplicity (but without loss of generality) we consider only one-period real discount bonds. Let $B_{t}$ denote the per capita quantity of these discount bonds purchased by the home country, which mature in period $t+1$. Let $r_{t}$ denote the world rate of return on these risk-free securities, and let $P_{t}^{B} \equiv\left(1+r_{t}\right)^{-1}$ denote the price of a discount bond purchased in period $t$.

The flow budget constraints for the economy whose financial trade is limited to the real bond are given by: 


$$
\begin{gathered}
P_{t}^{B} B_{t+1}+C_{t}+I_{t}=Y_{t}+B_{t} ; \text { home country } \\
P_{t}^{B} B_{t+1}^{*}+C_{t}^{*}+I_{t}^{*}=Y_{t}^{*}+B_{t}^{*} ; \text { foreign country. }
\end{gathered}
$$

We assume that bonds are in zero net supply in the world. Letting $\pi$ denote the fraction of the world population that lives in the home country, the world marketclearing condition for bonds is:

$$
\pi B_{t}+(1-\pi) B_{t}^{*}=0
$$

There is one last principle related to the extent of international financial market linkages:

PRINCIPLE \#9: The magnitude of a country's wealth effect depends on the market structure, since this governs the extent to which a country's risks can be diversified internationally.

\section{Model solution, measurement, and calibration}

The model described in the preceding section does not have an analytic solution, except in a small number of special cases. ${ }^{9}$ Because of the dynamic interactions of the labor-leisure choice with optimal capital accumulation, the equilibrium decision rules are generally not simple functions of the exogenous shocks. Thus our analysis of the model's predictions must necessarily involve studying approximate solutions to a particular, parameterized version of the model. This section describes the central issues involved in approximating and parameterizing the model.

\subsection{The Euler equation approach to model solution}

A great deal of research effort has recently been devoted to seeking fast, accurate solution methods for application to dynamic equilibrium models. In many models of interest, competitive equilibrium and Pareto optimum do not coincide (due, for example, to the presence of distortionary taxation or market incompleteness); thus, standard solution techniques cannot be used. Most of the methods currently in use begin from the observation that the system of first-order necessary conditions obtained from the model implicitly defines the equilibrium prices and quantities as nonlinear

\footnotetext{
${ }^{9}$ For example, one special case which admits an analytic solution is logarithmic utility, fixed labor input, and a 100\% rate of depreciation of capital, as in Long and Plosser (1983). See Cantor and Mark (1987, 1988) and Dellas (1986) for analyses of open economy real business cycle models which incorporate these assumptions and thus possess analytic solutions. Another case with an analytic solution has $\log$ utility and fixed labor input, but specifies capital accumulation as $K_{t+1}=B K_{t}^{1-\delta} I_{t}^{\delta}$, with $0<\delta \leq 1$.
} 
functions of the model's state variables (e.g., the capital stock and the exogenous shocks to productivity and government policies).$^{10} \mathrm{~A}$ variety of methods have been proposed for solving this nonlinear system of equations to obtain the equilibrium decision rules. ${ }^{11}$ One particular application of this general strategy is to take a loglinear approximation to the system of Euler equations, and then use standard linear systems procedures for solving this linear system of equations. We use the specific implementation of the procedure developed by King, Plosser, and Rebelo (1987); this method has been shown to be quite accurate for the one-sector neoclassical model when shocks to the economy are of realistic size (see, for example, Dotsey and Mao (1992)).

\subsection{Measurement and estimation of the productivity pro- cess}

A crucial element of the analysis is the measurement and estimation of the exogenous shocks to total factor productivity - the so-called "Solow residuals." These are defined as the residuals from the production functions, as follows:

$$
\begin{gathered}
\log A_{t}=\log Y_{t}-(1-\alpha) \log K_{t}-\alpha \log N_{t} ; \text { home country } \\
\log A_{t}^{*}=\log Y_{t}^{*}-\left(1-\alpha^{*}\right) \log K_{t}^{*}-\alpha \log N_{t}^{*} ; \text { foreign country. }
\end{gathered}
$$

Typically, researchers find that the following is an adequate representation of the joint stochastic process for productivity (constants and trends are suppressed):

$$
\left[\begin{array}{l}
\log A_{t} \\
\log A_{t}^{*}
\end{array}\right]=\left[\begin{array}{ll}
\rho & \nu^{*} \\
\nu & \rho^{*}
\end{array}\right]\left[\begin{array}{l}
\log A_{t-1} \\
\log A_{t-1}^{*}
\end{array}\right]+\left[\begin{array}{l}
\varepsilon_{t} \\
\varepsilon_{t}^{*}
\end{array}\right]
$$

where $E\left(\varepsilon_{t}\right)=E\left(\varepsilon_{t}^{*}\right)=0$. Under this specification, innovations to productivity which originate in one country $\left(\varepsilon_{t}\right.$ or $\left.\varepsilon_{t}^{*}\right)$ are transmitted to the other country via the "diffusion" parameter, $\nu$. The "persistence" parameter, $\rho$, is important for the serial correlation of the technology variable within a country. The variance-covariance matrix for the innovations to the productivity process is:

$$
E\left(\varepsilon_{t}, \varepsilon_{t}^{*}\right)\left(\varepsilon_{t}, \varepsilon_{t}^{*}\right)^{\prime}=\left[\begin{array}{cc}
\sigma_{\varepsilon}^{2} & \psi \\
\psi & \sigma_{\varepsilon}^{2}
\end{array}\right] .
$$

Direct estimation of the parameters of the productivity process has been hindered by the poor quality of international data on capital and labor input. For example, Backus, Kehoe, and Kydland (1992a) measure the productivity shocks as residuals from an aggregate production function, where labor input is measured as employment, and without a measure of capital input. More recently, Reynolds (1993) has

\footnotetext{
${ }^{10}$ Baxter (1991) describes this general approach in more detail.

${ }^{11}$ See, for example, the survey paper by Taylor and Uhlig (1990) and the papers cited therein, as well as Judd (1990).
} 
constructed measures of aggregate Solow residuals for several pairs of countries, using several different measures of labor and capital. ${ }^{12}$ Both sets of researchers find that movements in productivity are highly persistent $(\rho>0)$ (in fact, they are typically close to 1); and that innovations to productivity are positively correlated across countries $(\psi>0)$. The evidence on spillovers is mixed, with the Backus, et al. (1992) estimates suggesting important spillovers $(\nu>0)$, especially from the U.S. to other countries, but with Reynolds' estimates suggesting a much less important role for spillover effects. Although Backus, et al. and Reynolds both obtain point estimates that suggest the productivity shocks are trend-stationary, it is not possible to reject the null hypothesis of a unit root without spillovers at standard significance levels (see Baxter and Crucini (1993b)). Overall, Reynolds stresses that a substantial degree of uncertainty remains regarding the parameters of the productivity shock process.

\subsection{Comparing models with data}

A central component of the analysis is comparison of the model's predictions with the data, in order to evaluate the extent to which the model captures key features of the data, and to learn about aspects of the model that require further improvement. Since these highly restricted, small-scale equilibrium models cannot possibly beat an unrestricted VAR in a horse race of explanatory power, researchers in this area have tended not to use formal statistical methods to evaluate whether the models can be rejected by the data. Instead, a more informal approach to model evaluation has been pursued, in which the model's central moment predictions are compared with corresponding moments computed from the data. This section briefly reviews the issues involved in making this comparison..$^{13}$

A natural question arises as to when to filter in order to produce a stationary model. For example, should the productivity shock be rendered stationary before simulating the model? Or should the model be simulated with the "raw" productivity shock process, and then filtered? The correct procedure is the following. First, the researcher must estimate the forcing process (for productivity, government policy, terms of trade shocks, preference shocks) as best he can. There will generally be some form of nonstationarity, and it may be difficult to tell whether the productivity data are $\mathrm{I}(1)$ or just a near-unit-root trend-stationary process. The model should then be simulated with the estimated shock process. ${ }^{14}$ This approach will, of course, generally produce nonstationary model outcomes. For comparison with the data, both model and data should be filtered with the same filter. If we think of a business-cycle

\footnotetext{
${ }^{12}$ See Costello (1993) for a study of the properties of growth rates of cross-country, cross-industry Solow residuals.

${ }^{13}$ See King (1994) for discussion of the relationship between the evaluation methods of "real business cycle" analysis and those of traditional econometrics.

${ }^{14}$ The method of King, Plosser, and Rebelo (1987) will work even when the shocks are I(1) processes as long as they are not more explosive than $\sqrt{1 / \beta}$, where $\beta$ is the subjective discount factor.
} 
filter as the approximate band-pass described above, then this procedure compares the "business cycle components" of the model and the data in a way that is sensible.

The reason that it is incorrect to pre-filter productivity series to obtain a stationary forcing process is that the low-frequency and nonstationary components of the shock process will generally have implications for the behavior of the endogenous macro variables at all frequencies-including business-cycle frequencies. Thus we do not want to filter out the low-frequency and nonstationary components of the shock before simulating the model, because we may well have removed components of the shock process that are important for the way the model behaves at business-cycle frequencies.

Finally, it is important to note that pre-filtering to produce a stationary forcing process does not guarantee that the model will produce stationary outcomes. As stressed by Baxter and Crucini (1993b), and also present in the analyses of Rogoff (1992) and Sen and Turnovsky (1990), when international contingent claims markets are less than complete, exogenous shocks generally cause international wealth redistributions, which induce unit-root components into national consumptions, outputs, investments, labor inputs, and net exports.

\subsection{Calibration}

In most of the equilibrium open economy business cycle literature, the approach taken to obtaining a parameterized model is generally the so-called "calibration approach" advocated by Kydland and Prescott (1982). Under this approach, certain parameters of the model are chosen so that the model matches certain long-run properties of the data. For example, the model's parameters are set so that the model's steady state is consistent with the long-run experience of the U.S. economy with respect to growth rates, factor shares, proportion of time devoted to market activities, the average level of the real interest rate, and the rate of depreciation of capital. ${ }^{15}$ The parameterization of the shock process is estimated from the data; see section 4.2 above.

We parameterize our baseline model following King, Plosser, and Rebelo (1988); see their paper for more discussion of the parameterization. Under this parameterization, the steady state share of time devoted to market work is 0.20 ; the representative agent's discount factor, $\beta$, is 0.9875 ; the growth rate of labor-augmenting technical change, $\gamma_{X}$, is 1.004; capital depreciates at the rate of $2.5 \%$ per quarter; and labor income as a fraction of GNP is $\mathbf{0 . 5 8}$. The steady state share of government expenditures as a fraction of GNP is set at its approximate post-war US average of $20 \%$, and

\footnotetext{
${ }^{15}$ More recently, some researchers have advocated GMM estimation of selected parameters; see, for example, Christiano and Eichenbaum (1992). Under this approach, the estimate of (say) share parameters will be the same as under the calibration approach, since each will select the historical mean as the best estimate of the parameter. However, the GMM approach produces standard errors while the calibration approach does not.
} 
taxes as a fraction of GNP are set equal to their approximate current level of $30 \%$.

This model differs from most closed-economy real business cycle models in that we impose costs of adjustment in capital. Our near-steady-state analysis does not require that we specify a functional form for the adjustment cost function, $\phi$. We need only specify three parameters which describe the behavior of $\phi$ near the steady state. The first two of these parameters govern (i) the steady state value of Tobin's ' $q$,' and (ii) the steady state share of investment in national product. Effectively, these amount to specifying $\phi(I / K)$ and $\phi^{\prime}(I / K)$ at the steady state. We set these parameters so that the model with adjustment costs has the same steady state as the model without adjustment costs. Thus the steady state Tobin's ' $q$ ' is one, and the steady state share of investment is the same as in the model without adjustment costs. A third parameter which must be specified is the elasticity of the marginal adjustment cost function, $\eta$, which governs the response of $(I / K)$ to movements in 'q.' Since previous empirical studies have not estimated a cost of adjustment parameter for an open economy model such as ours, we use data on investment volatility to restrict this parameter, setting $\eta=15$ as in Baxter and Crucini (1993a,b).

Relative country size plays an important role in our analysis. In the context of our model, as in Crucini (1993a), country size is captured by population size. We have not incorporated cross-country differences in the central parameters of preferences or technology; nor have we introduced cross-country differences in per capita income, by making smaller countries systematically richer (per capita) or poorer than larger countries. This permits us to isolate the source of any differences in equilibrium outcomes in small versus large economies arising from country size, per se. For application to particular countries, one would of course wish to calibrate the two countries differently, so that each matched the long-run features of a specific economy.

\section{Business cycle and current account dynamics in the basic model: Productivity shocks}

This section studies the business-cycle and current account responses to shocks to total factor productivity. We compare the domestic and international responses under alternative assumptions for the stochastic process governing productivity, and under alternative assumptions regarding the degree of asset market completeness. ${ }^{16}$ Our approach is to study a sequence of economies, beginning with the prototypical small open economy facing a fixed world interest rate, and working toward analysis of a large economy (an economy which can affect the world interest rate) with variable labor input. In this progression, we will encounter the principles enumerated in section 3 above.

\footnotetext{
${ }^{16}$ For related analyses of general equilibrium models with incomplete markets, see Conze, Lasry, and Scheinkman (1990), and Kollman (1992).
} 
As is usual in general equilibrium analyses, shocks induce both wealth and substitution effects, which in non-quantitative models often results in an overall response of indeterminate sign. A benefit of our quantitative approach is that we can evaluate the relative importance of these effects in determining the overall response of an economy to a particular shock. Our method for decomposing the effects of shocks is described in the first sub-section below.

\subsection{Hicksian decompositions}

Economists have long found it useful to decompose the response of individuals to a shock into responses due to variations in wealth or income, and responses due to variation in prices. One particular decomposition, due to Sir John Hicks (1939) has long been used in comparative statics analyses. A version of this decomposition for dynamic models has been developed by King (1990). These "Hicksian decompositions" are very useful for understanding the equilibrium response of a dynamic economy to shocks of various sorts, and we shall use them extensively throughout this chapter. This sub-section describes in an intuitive way how these decompositions work.

Consider an economy in which the time path of consumption has been disturbed by a shock. In particular, suppose that the shock has caused consumption and labor input to deviate from their prior steady-state paths as illustrated in Figure 3. In general equilibrium, the shock will typically cause disturbances to the path of real wages and also to the path of interest rates. Further, the shock will have an effect on the individual's wealth as measured by the present value of lifetime expected utility.

Following Hicks, the wealth effect is measured as follows. Compute the change in lifetime expected utility which occurs because of the displacement of consumption and leisure from their steady state paths. Next, compute the constant changes in consumption and leisure which produce the same change in lifetime utility, while preserving the intratemporal efficiency condition for consumption and leisure. We will call this constant amount the "wealth effect" of the shock, the consumption component of which is sketched in Figure 3. At each point, the difference between the actual value of consumption or leisure and the amount due to the wealth effect is due to substitution effects associated with variations in the wage rate and the interest rate. To compute the wage rate effect of a shock, imagine holding individuals' wealth levels fixed at their initial, steady-state level, and imagine that the interest rate is also at its steady state level. Now, ask the consumer how his consumption and leisure choices would be altered if he were faced with the alteration in the time path of wages induced by the shock. These alterations in consumption and leisure are the wage rate effects of the shock. The interest rate effects are computed in a similar fashion, by tracing out the effects on consumption and leisure of the interest rate response, holding wages and wealth fixed at initial steady-state levels. 


\subsection{Dynamic response to a permanent productivity shock}

To begin our analysis of the general equilibrium effects of shifts in total factor productivity, we consider an unanticipated, permanent increase in the level of total factor productivity in the home country. We will develop our understanding of the importance of endogenous interest rate determination, variable labor, and the effect of country size by studying a sequence of economies, as follows. The first sub-section below considers an economy with fixed labor input and which is sufficiently small that the effect on the world interest rate of country-specific shocks is negligible. The next sub-section considers the same small open economy, but with variable labor. The third sub-section studies a "large" country - a country whose GDP is half the world's GDP - with variable labor input. This example allows us to study the importance of interest rate effects in the overall dynamic response to the productivity shock.

\subsubsection{A small open economy with fixed labor input}

A natural starting point is a small open economy with fixed labor input. In this economy, there will be only wealth effects of shocks: interest rate effects will be absent because of the small country assumption, and wage effects will be absent because labor input is fixed. Consider an unanticipated, permanent increase of $1 \%$ in the country's level of total factor productivity. The country represents only $1 \%$ of world GDP, so that the effect of country-specific shocks on world aggregates is essentially zero. The response of domestic macroeconomic aggregates are plotted in Figure 4: solid lines denote the response of the country when it has access to complete contingent-claims markets; dashed lines denote the response of the economy when its financial trade is limited to a non-contingent real bond. Units of output are chosen so that the direct effect of the $1 \%$ increase in productivity is a one-unit increase in output.

Output and investment: The permanent increase in the level of productivity stimulates an investment boom and a rising path for output. This is an application of principle \#8: investment depends positively on the marginal product of capital. The long-run effect on output is 1.72 goods units. ${ }^{17}$ The response of output and investment is the same across asset structures because labor input is assumed to be fixed. That is: the only determinant of investment and output dynamics is the physical product of capital which, due to the fixity of labor, is the same across asset structures.

\footnotetext{
${ }^{17}$ The one-unit increase in output on impact is due to the productivity shock alone, since capital is predetermined and labor input does not change. The long-run effect can be derived from the steady state condition that $\partial F / \partial K=r+\delta$. Differentiating this, and using eqn. (5) yields $d A / A=$ $\alpha(d K / K)$, or $d K / K=(1 / \alpha) d A / A$. Thus $d Y / Y=d A / A+(1-\alpha) d K / K$ or, substituting, for $d K / K$ and setting $\alpha=0.58$ (this is labor's share), we have $d Y / Y=(1 / \alpha) d A / A=1.72 d A / A$.
} 
Consumption: The consumption response, in contrast to output and investment, is sensitive to the asset structure. Under complete markets, individuals pool all idiosyncratic risks; in the "bond economy," they simply use the non-contingent real bond to effect consumption-smoothing in response to idiosyncratic wealth shocks. Since the world wealth effect of a permanent productivity shock in the small economy is approximately zero, under complete markets the consumption response in the home (small) country is also approximately zero. However, the productivity shock represents a significant alteration in home country wealth, and in the bond economy the wealth effect of the shock is concentrated on the home country. That is: absent risk-pooling, a permanent increase in productivity represents a significant, positive wealth shock to the home country, and consumption correspondingly rises. These implications reflect principles \#1 and \#9: consumption depends on wealth, and the wealth effect of a shock depends on the asset structure.

Notice, in particular, that consumption rises on impact by more than the output. Since output continues to rise after the impact period, permanent income theory predicts that consumption should rise by more than output. ${ }^{18}$ Further, the predicted response of consumption is flat after the first period since the interest rate is unaffected by the shock. Because this economy is too small to affect interest rates and because labor input is fixed, there is only a wealth effect on consumption.

Net exports and the current account: Finally, we consider the response of net exports of goods as well as the response of the current account. Net exports are defined in the context of our model as $Y-C-I-G$, where our output measure is GDP. The current account adds to net exports net interest payments on domestic debt held abroad and other net transfers. In the bond economy, it is straightforward to compute the current account in a way that is consistent with NIPA practice. However, many researchers have noted that current NIPA practice produces a less-than-ideal measure of the current account, since it fails to incorporate shifts in net foreign asset holdings that occur (for example) due to unrealized capital gains or losses on foreign assets (see, for example, Baxter and Crucini (1993a), Obstfeld (1986), and Stockman and Svensson (1987)). In the complete markets economy, however, measuring the current account is further complicated by the fact that there are a variety of ways to decentralize the equilibrium (by trading insurance claims, in essence) and current NIPA practice would not necessarily appropriately capture all of these. We choose to avoid this issue entirely by just reporting net exports when discussing the complete markets economy.

Turning, then, to the behavior of net exports (which we will also refer to as the "trade account") we see that there is a trade deficit on impact under both complete

\footnotetext{
${ }^{18}$ Recall that capital is predetermined and labor is fixed, so that the impact effect on output is simply due to the direct productivity effect. Further, the presence of adjustment costs is responsible for the upward slope to the dynamic response of output: absent adjustment costs, output would jump to its new steady state level in period 2.
} 
and incomplete markets structures. In the complete markets economy, the transfer of goods from the foreign country in the impact period is necessary so that investment can rise by the socially optimal amount in response to the shock (recall that investment increased by more than output on impact). In subsequent periods, output exceeds investment, and the excess is shared equally as an increase among all individuals in the world. Although the world is so large that the resulting increase in consumption is small for each individual, in the home country the effect is a significant trade surplus from period 2 onward. However, there is no accompanying increase in foreign indebtedness to the small country-the trade surplus may be viewed as representing payments in fulfillment of a contingent-claims contract that specified these payments in the event that the home country experienced an increase in productivity.

In the bond economy, net exports move to a deficit position on impact, and remains in deficit for the first five years of the transition period (20 quarters). This is due to the larger increase in consumption in the bond economy relative to the complete markets economy; recall that the output and investment responses were the same across market structures. Absent complete markets, however, the trade deficit implies that the home country is selling bonds to the foreign country to finance the rise in consumption. Thus, beginning in period 2, the home country will be paying interest on their foreign debt in addition to running a trade deficit, so that the current account is in deficit along the entire transition to the new steady state.

Investment, net exports, and the current account: Finally, consider the relationship between investment and the current account in the bond economy. Investment increases on impact by 1.11 goods units, while net exports fall on impact by 1.30 goods units. As Glick and Rogoff (1994) have noted, permanent increases in productivity lead to the implication that the current account should respond by more than investment in a small open economy with fixed labor and a constant interest rate. However, Glick and Rogoff provide empirical evidence that current account responses are typically smaller in magnitude than investment responses. We return to this puzzle in section 5.2 .3 below.

\subsubsection{A small open economy with variable labor input}

Having studied the response of the prototypical small open economy with fixed interest rates and fixed labor input, we turn next to the question of how variable labor input affects the dynamic response to productivity shocks. Variable labor is important for two reasons. First, variations in the quantity of labor input alter the marginal product of capital and hence affect investment (principle \#8). Prior work by Baxter and King (1993) and others have stressed that the dynamic interactions of capital and labor are important for understanding the dynamic response of economies to

a variety of shocks. Second, variable labor input will lead to important differences across asset structures in the responses of investment and output, compared with the 
economy studied above in which labor input was fixed. We shall see that alterations in asset structure can lead to significant alterations in the response of labor and hence in the response of investment and output. These effects arise because the wealth effect of shocks is sensitive to asset structure and, as we demonstrate below, because the wealth effect on labor input is predicted by these models to be empirically quite important,

Output, investment, consumption, and labor input: Figure 5-A plots the response of macroeconomic aggregates to the same unexpected, $1 \%$ increase in productivity studied in the previous section. Beginning with analysis of the complete markets economy, we see that labor input rises on impact and continues to rise toward the new steady state, as does output. Investment also rises on impact, but declines toward the new steady state. Comparing the magnitudes of the investment and output responses to those of the fixed-labor economy studied above, we find that investment increases on impact by more than three times as much in the variable-labor economy ( 3.4 goods units, compared with 1.1 with fixed labor), while the complete markets output response is almost twice as large with variable labor. In the new steady state, the change in output in the variable-labor economy is nearly five times higher, compared with the fixed-labor economy.

What are the economic mechanisms leading to such a strong response in the variable-labor economy, under complete markets? Clearly, it cannot be substitution effects induced by variation in the real interest rate, since these have been ruled out by the small country assumption. Figure 5 -B plots the Hicksian decompositions of the response of consumption and labor. This figure shows that, under complete markets, the wealth and wage effects on consumption are approximately equal and of opposite sign, so that the overall consumption effect is approximately zero. Under incomplete markets, both the wealth and wage effect on consumption are positive. Adding variable labor has incorporated dynamics associated with principle \#5: labor input (and thus income and consumption) are affected by temporary variations in wage rates.

Turning to the behavior of labor input, we see that there is a substantial wealth effect operating under complete markets, in accordance with principle \#3. That is: the negative wealth effect associated with complete markets is translated into a substantial increase in labor input arising from this channel. On impact, there is a mitigating effect of the wage rate, although the wage effect on labor input becomes positive as well once the capital stock has accumulated sufficiently. In the bond economy (the incomplete-markets economy) the wealth effect on labor input is negative (i.e., individuals are wealthier, so they choose to work less hard). Although the wage effect is positive, the net effect on impact is a decline in labor input. However, the wage effect rises through time and in the new steady state, labor input has risen.

To be more specific about the way that wealth effects operate in this economy, it is useful to consider the type of state-contingent contracts that could support 
the social optimum of complete risk-pooling. The optimal response to a countryspecific productivity shock is for residents of that country to work much harder in response to the shock, in order to take advantage of the increase in productivity (recall that labor is assumed to be immobile across countries). The increase in the available supply of consumption goods produced by this additional labor input is then shared equally across all individuals in the world, regardless of nationality. Since the originating country is so small, the increase in consumption involved is negligible, while the increase in work effort in the home country is substantial. Overall, the level of utility enjoyed by residents of the home country falls when they experience a positive productivity shock, since they work much harder and consume only a little bit more. Put differently, individuals in the home country experience a negative wealth shock as a consequence of the positive home country productivity shock. The negative wealth shock is the main force behind the stronger response of labor input and hence, investment and output, compared with the complete markets model with fixed labor input. ${ }^{19}$

Returning to figure 5-A, we see that the responses of investment and output are different across asset structures when labor input is variable, in contrast to the predictions of the fixed-labor model studied earlier. The central reason for these differences is differences in the wealth effects of the productivity shock across asset structures. In particular, in the bond economy an increase in home country productivity leads to a positive wealth effect in that country. Since individuals value both consumption and leisure, they respond to a positive productivity shock (a positive wealth shock) by increasing consumption and decreasing labor supply. This explains the decline in labor supply in the home country on impact. The rising path of labor input over time is due to the rising path of wages; as capital is accumulated the marginal product of labor rises, making it more profitable for individuals to work more. The smaller response of labor in the bond economy explains why investment and, hence output responses are also smaller than in the complete markets economy. In fact, the investment and output responses are smaller in the variable-labor bond economy than they were in the fixed-labor economy studied in the subsection above. This is due to the fact that, with fixed labor, the positive wealth effect of the shock does not cause labor input to decline, as it does in the current experiment.

Net exports and the current account: The responses of net exports and the current account in the variable-labor economy are surprisingly similar to those in the fixed-labor economy studied above (these are not plotted in Figure 5-A). In particular, the trade account moves into deficit on impact under both market structures, but

\footnotetext{
${ }^{19}$ If consumption and leisure enter non-separably in the period utility function, consumption rises by more under complete markets in the economy experiencing the shock. This is necessary to satisfy the intra-temporal efficiency condition for consumption and leisure. However, the effect is not large enough to overturn the implication that the wealth effect of a positive productivity shock is negative under complete markets.
} 
rapidly moves into surplus in the complete-markets structure as the home economy begins to transfer goods abroad as part of the risk-pooling agreement. The current account is unaffected in the complete-markets economy for reasons described above, while it registers a deficit throughout the transition period in the bond economy.

\subsubsection{A large economy with fixed labor}

In a large economy with fixed labor, there are both wealth and interest rate effects of shocks, but no wage effect. In the small open economy with fixed labor input, ther were only wealth effects. The addition of interest rate effects changes the response only slightly, compared with that case. Investment and output responses continue to be invariant to asset structure, while consumption rises by more under incomplete markets. The addition of the interest rate effect means that the consumption response displays an upward slope over time, reflecting the fact that the interest rate rises in response to the shock and then falls back toward the initial steady state level.

However, there is one point of special interest that arises in this case. With fixed labor supply (or simply if labor supply is very inelastic), on impact the current account registers a deficit that is smaller in absolute value than the increase in investment. This is an important result, because it shows that current account movements can be smaller than investment responses, as Glick and Rogoff (1994) find in the data. That is: with endogenous interest rates, it is no longer necessarily the case that the response of the current account to a permanent productivity shock is larger in absolute value than the response of investment.

\subsubsection{A large country with variable labor}

Finally, we consider the effect of a permanent productivity shock on a large country with variable labor. This experiment combines all the important elements of our general equilibrium framework: endogenous interest rate determination, dynamic interactions of capital and labor, and significant effects of country size. In particular, it adds interest rate effects (associated with principles \#2 and \#4) to the dynamic effects operating in the small economy with variable labor.

Figure 6-A plots the response of macroeconomic aggregates in the home and foreign country to the same permanent, unanticipated $1 \%$ increase in home country productivity. In many respects, the effects of allowing variable labor in the large economy are similar to the effects described above for the small economy with variable labor. Specifically, the variable-labor economy displays investment and output responses that depend on asset structure. The reason is that the wealth effects of the shock on labor input differ markedly across asset structures. Under complete markets the positive productivity shock represents a negative wealth shock; in the bond economy, the shock produces a positive wealth effect. Labor input consequently increases in the complete markets economy, but falls in the bond economy. 
Figure 6-B sheds more light on the various components of the responses by plotting the associated Hicksian decompositions. The addition of variable labor to the large economy induces wage effects on consumption which this figure shows are very important to the overall response. In the complete markets economy, the wage effect on consumption is positive-sufficiently so that it outweighs the depressing effect of the wealth and interest rate effects. In the bond economy, the positive wage effect reinforces the positive wealth effect in leading to a stronger overall effect on consumption. In terms of the labor response, the wage effects are of similar magnitude to the wealth effects, and under both asset structures the wage and wealth effects are of opposite sign. These effects are then combined with the interest rate effect, which is positive under both asset structures. The net effect on the bond economy is one in which the wealth effect dominates: labor input initially falls in response to the shocks.

We can gauge the effect of country size and interest rate variation by comparing the responses of the small and the large countries (Figures 5 and 6). Compared with the small country, the large country's investment response is smaller, because the large-country productivity shock drives up the world interest rate. The initial increase in consumption is also smaller in the large country, as the increase in the interest rate induces individuals to postpone consumption. However, the net effect on net exports and the current account of incorporating variable labor is minimal, as it was in the small economy.

\subsection{Dynamic response to temporary productivity shocks}

In the preceding section we studied the response of a sequence of model economies to an unexpected, permanent increase in productivity. While it is natural to think of technical innovation as something that is permanent, the innovation process may be trend-stationary rather than difference-stationary, as assumed above. In fact, empirical investigations of the stochastic process for productivity typically generate point estimates that suggest trend-stationarity, although the null hypothesis of a unit root cannot usually be rejected. This sub-section investigates how our predictions for the response to productivity shocks is altered when the shocks are assumed to be trend-stationary.

\subsubsection{Trend-stationary shocks with spillovers}

Backus, Kehoe, and Kydland (1992a) estimated a productivity process for the U.S. vs. six OECD countries, using quarterly post-war data on output and labor input. Their "symmetrized" version of their preferred estimate for the log of productivity is given by the process below (omitting constants and trend terms):

$$
\left[\begin{array}{l}
\log A_{t} \\
\log A_{t}^{*}
\end{array}\right]=\left[\begin{array}{ll}
.906 & .088 \\
.088 & .906
\end{array}\right]\left[\begin{array}{l}
\log A_{t-1} \\
\log A_{t-1}^{*}
\end{array}\right]+\left[\begin{array}{l}
\varepsilon_{t} \\
\varepsilon_{t}^{*}
\end{array}\right]
$$


The estimate of the contemporaneous correlation of the innovations to the productivity process was $\psi=0.258$. Under this specification, shocks to productivity are highly persistent, and shocks originating in one country are transmitted to the other country at the rate of $8.8 \%$ per quarter. The shocks are trend-stationary, however, since the largest eigenvalue of the matrix multiplying lagged productivity is $\rho+\nu=0.906+0.088=0.994$.

Consider the version of the model with two equally-sized countries and variable labor, in which there is a $1 \%$ shock to total factor productivity which originates in the home country. The response of both countries is plotted in Figure 7. The most striking impression from this figure is how similar the responses are between the complete markets and bond economies. In the case of permanent shocks, there were important differences in the wealth effects across asset structures, as illustrated by the Hicksian decompositions. These differential wealth effects were responsible for very different responses of labor input, investment, output, and consumption across asset structures. In the present example, the extreme similarity of the responses across asset structures can be traced to the same reason: the wealth effect of the shock is nearly identical across the two asset structures. That is: a shock that originates in the home country is transmitted to the foreign country rapidly enough that the foreign country can sustain a consumption path nearly as high as that obtained under complete risk-pooling. The only financial asset needed by the foreign country is a riskfree real bond, which allows residents of the foreign country to borrow for the purpose of consumption while waiting for the positive productivity shock to be transmitted to their country. Since this is the single financial asset provided in the "bond economy," restrictions on other types of asset trade have minimal effect! ${ }^{20}$

Net exports and the current account Finally, we turn to the behavior of net exports and the current account. In contrast to a permanent shock, the trendstationary-with-spillover shock leads to surpluses in both the trade and current accounts for the country in which the shock originates (these are not plotted). This effect is easy to understand, once we recall that the shock leads foreigners to decumulate bonds to sustain consumption while waiting for the shock to arrive. Thus the foreign current account deficit must be offset by a current account surplus in the home country. However, the implication that output and investment booms are associated with current account surpluses runs counter to the empirical findings of Sachs (1981) and, more recently, Glick and Rogoff (1994). Even without transmission, the productivity shock must have its largest autoregressive root larger than about 0.99 to generate a current account deficit in response to an unexpected increase in productivity.

Compared with permanent shocks, temporary shocks generate a smaller wealth effect together with increased opportunities for intertemporal substitution (principles $\# 2$, \#4, and \#6). This is most evident in the response of home country labor input which, under incomplete markets, rises in response to the shock (recall that it fell

${ }^{20}$ For further discussion, see Baxter and Crucini (1993b). 
in the case of a permanent shock). Labor input rises in this case for two reasons: first, the substitutions associated with wages are stronger, as the productivity shock is not expected to last forever; and second, the wealth effect which depresses labor input is smaller, the less persistent is the shock. Further, the higher are spillovers, the higher is the common wealth effect of the shock across countries in the absence of any risk-sharing. In conclusion, we find that closing asset markets, with the resulting alteration of relative wealth effects, is less important (i) the less persistent are shocks; and (ii) the more rapid is the international transmission of shocks.

\subsubsection{Permanent effects of temporary shocks}

An important feature of the two-country general equilibrium model is that temporary shocks generally have permanent effects on macroeconomic quantities when countries do not have access to complete contingent-claim markets. This is in sharp contrast to the standard, closed-economy 'real business cycle' model such as that of King, Plosser, and Rebelo (1988) which was carefully constructed so that trend growth in real wages would not lead to trend growth in labor input (because of exactlyoffsetting income and substitution effects on labor input). In the complete-markets version of our two-country model, the resulting risk-pooling means that there are no ex-post wealth redistributions, which preserves the result that steady-state labor input is invariant to temporary shocks to technology. When asset trade is restricted, however, international wealth redistributions arise whenever a shock has a countryspecific component, and the resulting alteration in relative wealth levels leads to permanent shifts in labor input in both countries.

The intuition is easily developed with reference to the standard, permanent-income theory of consumption, as in Hall (1978). When a permanent-income consumer is faced with a change in the present value of his income, whether it be due to a temporary of a permanent shock, he responds by permanently changing his level of consumption. If the individual values both consumption and leisure, both respond in a permanent way to changes in wealth. In the context of this model, even temporary changes in productivity affect relative wealth levels in the bond economy and, hence, even temporary productivity shocks have permanent effects on labor input, investment, output, consumption, and net exports.

This implication is important, since most macroeconomists believe that macroeconomic quantity variables contain stochastic trends. Our analysis has shown that, so long as asset markets are less than perfectly complete, even temporary shocks will be sufficient to induce stochastic trends in endogenous quantity variables. In particular, it is not necessary that the forcing process have a unit root in order for shocks to that process to produce unit roots in macroeconomic time series. 


\section{Business-cycle implications of the one-good model}

This section explores the extent to which the one-good model matches the salient features of international business cycles. The first of the three main sections below compares the predictions of the model to the stylized facts presented in section 2 . The second sub-section addresses the model's predictions for differential response in small vs. large countries. From this analysis, three main puzzles will arise which are addressed in the last sub-section.

\subsection{How well does the model match empirical business cy- cles?}

To put more structure on this question, we ask how well the one-good model matches empirical business cycles when driven by productivity shocks alone. The estimation of the productivity shock process was discussed in section 4.2 above, and the main finding was that shocks to productivity are highly persistent, are correlated across countries, and show some weak evidence of transmission from one country to another. Estimates of the persistence of shocks are generally quite high, especially for shocks originating in the U.S. and, as noted earlier, the null hypothesis of a unit root cannot be rejected. We therefore take as our benchmark case the following parameterization of the productivity process (15): $\rho=\rho^{*}=0.995, \nu=\nu^{*}=0.0 .^{21}$ The variancecovariance structure of the error terms is (16), with $\sigma_{\varepsilon}^{2}=0.73$, and $\psi=0.19 .^{22}$

The results of the simulations for the benchmark economy are reported in Table 2 - $\mathrm{A}$; the country is assumed to represent one-half of the world $(\pi=1 / 2)$. Since the model was parameterized to match the U.S. economy, the within-country statistics should resemble the U.S. statistics from Table $1 .{ }^{23}$ Results are reported for two market structures: the complete markets economy, denoted "CM" in the table, and for the incomplete markets economy, denoted "IM," in which only goods and noncontingent real bonds are internationally traded.

Within-country business cycles: Output is more volatile in the complete markets economy (with a standard deviation of $1.69 \%$ per quarter) compared with the incomplete markets economy (1.04\%), although neither model replicates the level of volatility found in the post-1970 data-the corresponding statistic for U.S. output

${ }^{21}$ This specification is in the range generated by prior researchers, with a largest eigenvalue of 0.995 approximately equal to the eigenvalue of 0.994 implied by the symmetrized parameterization of Backus, et al (1992). However, Reynolds (1993) finds little statistical support for international "spillovers" of technology, so we set these equal to zero (i.e., $\nu=\nu^{*}=0$ ).

${ }^{22}$ These are the estimates of the variances and covariance estimated by Backus, Kehoe, and Kydland (1992a) in their "symmetrized" case; they are also in the range found by Reynolds (1993) for a variety of approaches to measuring the Solow residuals.

${ }^{23}$ The moments reported in Table 2 were obtained after applying the same band-pass filter that was used to filter the data for Table 1. 
is $2.00 \%$. The higher volatility of the complete markets economy derives from the substantially larger labor supply responses in that economy, as discussed in section 5 above. The higher labor volatility naturally induces higher investment volatility, and the combination of the two factors makes output much more volatile under complete markets.

In terms of relative volatility, consumption is smoother in the complete markets economy, while investment is more volatile for the reasons outlined above. Interestingly, the relative volatility of net exports is unaffected by market structure. Similarly, the persistence of the macro aggregates (measured as autocorrelation at lag 1) is largely unaffected by market structure.

By contrast, the pattern of within-country comovement is affected by market completeness. Because of the insurance characteristics of the complete markets equilibrium, consumption is much less correlated with output under that structure than with incomplete markets (under complete markets, the correlation is too low relative to the data presented in Table 1). But labor is more highly correlated with output under complete markets - again, as a result of the optimal risk-sharing character of that equilibrium (comparison with the data here is problematic, since the data measure employment and the model's predictions are for total hours worked). Finally, we note that net exports are roughly uncorrelated with output under complete markets, but are negatively correlated (as in the data) under incomplete markets. We conclude from this that the model does a reasonable job of replicating the within-country character of business cycles, with the incomplete markets version of the model performing somewhat better along several dimensions. ${ }^{24}$

Cross-country business cycles: We turn next to the model's predictions for crosscountry business-cycle statistics. Several of the key statistics are presented in the last two columns of Table 2-A: these are the international correlations of output; consumption; investment; and labor input, as well as the saving-investment correlation. The complete markets model predicts output correlations that are too low, relative to the data, together with consumption correlations that are much too high. The incomplete markets model does much better, predicting positive correlations of both outputs and consumptions, but with consumption correlations that are lower than output correlations (although both appear somewhat too low, relative to the data). Both market structures predict negative international correlation of investment and labor input and both predict substantial positive correlation between national saving and investment. Each of these findings represents a puzzle, and we return to these puzzles in section 6.2 below.

The effect of "spillovers": To investigate the importance of international "technology spillovers" for business cycles, panel B of Table 2 simulates the model using the

\footnotetext{
${ }^{24}$ However, van Wincoop (1993) finds that the standard real business cycle model cannot produce enough volatility in the real interest rate, compared with the data.
} 
symmetrized parameterization of Backus, Kehoe, and Kydland (1993). Under this parameterization, $\rho=\rho^{*}=0.906$ and $\nu=\nu^{*}=0.088$, with the variance-covariance matrix as in the benchmark case. Inspection of this panel shows that there are few differences between the complete and incomplete market economies. Apparently, the spillovers of technology are strong enough that virtually all shocks are common shocks, so that there are very limited opportunities for international risk-sharing. The only difference between the two countries is that one country experiences the shock before the other, so that one country dissaves (decumulates debt) while waiting for the shock to arrive. The single financial instrument in the economy-the noncontingent bond-is the perfect vehicle for this consumption-smoothing.

Overall, this version of the model performs more poorly than our benchmark version along two key dimensions. First, net exports are positively correlated with output, while these are negative in the data. Second, cross-country output correlations are negative, while consumption correlations are 1.00 (even with incomplete markets). This analysis suggests that common shocks are more likely to be the reason for observed international comovement, rather than transmission of shocks over time.

\subsection{Business cycles in small vs. large countries}

This model predicts a natural link between country size and the volatility of macroeconomic aggregates, which stems from the endogenous response of the interest rate to disturbances originating in large economies. Specifically, positive productivity shocks increase the marginal product of capital and stimulate investment. At the same time, however, the shock drives up world interest rates and crowds out investment. This effect is stronger, the larger is the country in question. As a result, the model predicts that investment should be more volatile in smaller countries because smaller countries effectively face a flatter supply curve for capital (i.e., they can import a great deal of capital without significantly affecting the world interest rate). Second, current accounts should be more volatile in smaller economies due to higher investment volatility, combined with the fact that a greater share of investment is financed abroad.

The empirical relationship between economic size and business cycle characteristics has been studied by Crucini (1992), Head (1992), and Zimmerman (1991). These studies find that larger countries, such as the members of the G-7, have less volatility in investment, consumption, and the trade balance compared with smaller countries. Further, the G-7 countries have larger correlations between savings rates and investment rates, with smaller countries having a stronger tendency for investment booms to be associated with declines in the trade balance. The standard, one-sector open economy model predicts these findings.

Other quantitative-theoretic analyses of small open economies subject to a variety of shocks have recently been carried out by Cardia (1991), Mendoza (1991), and Correia, Neves, and Rebelo (1994). Leiderman and Razin (1991) construct an optimizing 
model of the current account that is similar to the models developed in the rest of the literature, but they estimate the decision rules of their model using two-stage least squares. Gaudin and Yi (1993) explore the empirical importance of the real interest rate for trade balances of small open economies. They find that a sustained, one-percent increase in interest rates raises the trade balance by about $0.40 \%$, which suggests that interest rate shocks are an important source of fluctuations in the trade balance for small economies.

\subsection{Three puzzles}

Our analysis of the business-cycle predictions of the one-good model has uncovered three puzzles which are worth further discussion.

\subsubsection{The saving-investment puzzle}

Many authors, notably Obstfeld (1986) and Tesar (1991), have documented the strong time-series correlation between national savings and national investment. It would be natural to conclude from this that international financial markets must not be sufficiently open to allow individuals to separate consumption decisions from investment decisions. However, Sachs (1981) found that current account deficits tended to be associated with investment booms, suggesting that international financial markets are sufficiently open to allow flexible foreign financing of investment; this finding was recently confirmed by the analysis of Glick and Rogoff (1994). The apparent puzzle was resolved by Baxter and Crucini (1993a) who showed that substantial, positive saving-investment correlations are a robust implication of the basic model, even with complete contingent-claims markets. Further, the model rationalizes the Sachs findings. These results show that the time-series saving-investment correlation is not an informative statistic concerning the degree of international financial integration. ${ }^{25}$

\subsubsection{The consumption correlation puzzle}

The second puzzle is that international consumption correlations are lower than international output correlations, but that the complete markets model (and the model with spillovers, regardless of asset structure) predicts that consumption correlations should exceed output correlations. To appreciate how odd the observed pattern of correlations really is, consider two extreme cases: the first being complete risk-pooling, and the second being the Keynesian consumption function, $C=\alpha Y$. Under complete risk-pooling, as we have seen, consumptions are perfectly correlated (or nearly so) as individuals diversify away all idiosyncratic variation in consumption. But even with the Keynesian consumption function, the cross-country correlation of consumption

\footnotetext{
${ }^{25}$ Many other authors have also shown, in the context of non-quantitative models, that saving and investment can be positively correlated without restrictions on asset markets; see, for example, Engel and Kletzer (1989), and Finn (1990).
} 
should be exactly the same as the cross-country correlation of output. It is particularly striking, then, that our benchmark model with incomplete markets can rationalize output correlations that exceed consumption correlations. Several other authors have also provided examples of economies which can replicate observed consumptionoutput correlations: see, for example, Reynolds (1992) and Devereaux, Gregory, and Smith (1992).

Lewis (1993) undertakes an empirical investigation of the forces behind the low international correlation of consumption. She analyzes the Euler equation for efficient consumption choice, and investigates whether modification of the model in terms of (i) variable leisure; (ii) addition of consumer durables and nontraded goods; and (iii) capital market restrictions are important for explaining the low international correlation of consumption. She finds that variable leisure is not important for resolving the puzzle, but that adding durables and nontradables go a long way toward producing the finding that there is international risk-pooling in tradable goods. Further, the evidence for risk-pooling is substantially stronger in countries without restrictions on international capital movements. In related work, Atkeson and Bayoumi (1991), Crucini (1993), and van Wincoop (1992a,b) find that risk pooling tends to be stronger across regions within countries than across national boundaries.

\subsubsection{The international comovement puzzle}

The third puzzle is that our basic model consistently predicts that investment is negatively correlated across countries, and also predicts negative cross-country correlation of labor input. However, these correlations are positive in the data. The one-good character of the model, combined with the international mobility of physical capital, leads to a strong tendency to move capital to its most productive location in response to persistent productivity shocks. Given that capital moves to the more-productive location, the returns to labor rise sharply in the country experiencing the investment boom, while they are (relatively) low in the other country. In an early analysis of the "comovement problem," Rebelo (1987) showed that labor input in different locations would be negatively correlated unless the correlation of the innovations to the location-specific shocks exceeded about 0.95. Although the innovations to Solow residuals are positively correlated across countries, this correlation is not strong enough to overcome the natural mechanisms leading to negative comovement.

For a model to generate realistic international comovement of labor and investment, it seems be necessary to develop a model with multiple goods and important linkages between the goods, either on the consumption or the production side. We return to this topic in section 8 below. 


\section{Fiscal shocks}

This section studies the business cycle and current account responses to fiscal shocks. In particular, we study the responses to unanticipated variations in government purchases and tax rates, under alternative asset market structures. We investigate whether the model lends support to the view that government budget deficits lead to trade and current account deficits, and use our model to interpret the results of the large empirical literatures on the "twin deficits" and the deficit-interest rate link. ${ }^{26}$

\subsection{Government purchases}

This sub-section studies the dynamic response of both small and large countries to alterations in government purchases. Shocks to government purchases historically have had both temporary and permanent components, with the most significant movements in the temporary components associated with wartime periods. We will confine our attention to analysis of government purchases which do not directly affect private productive opportunities and which do not alter the marginal utility of consumption of privately-produced goods. ${ }^{27}$

\subsubsection{Permanent shocks}

As a first experiment, consider an unanticipated, permanent increase in government purchases which occurs in a small open economy with fixed labor input. The increase in government purchases represents a pure wealth shock. Throughout, we assume that variations in government purchases are financed by changes in government debt which will ultimately be repaid by increases in lump-sum taxes (decreases in transfers). We call this debt "Ricardian debt" because Ricardian equivalence holds in this model. ${ }^{28}$ Since the country is very small, the shock to world wealth is approximately zero. Under complete markets, therefore, there will be approximately zero change in consumption, both at home and in the foreign country. When markets are incomplete, so that the small country can trade a risk-free bond but cannot trade securities

\footnotetext{
${ }^{26}$ This section draws heavily on Baxter (1993).

${ }^{27}$ Baxter and King (1993) use a one-sector model of a closed economy to study shocks to government purchases which are valued in consumption; which increase the private marginal product of capital; and which augment the stock of government-provided capital. They found that these modifications were of minor quantitative importance, except for government capital. Additions to the government capital stocks can be quantitatively important if the government capital stock is under-provided, as has been argued by Aschauer (1989).

${ }^{28}$ Arvanitis (1994) and Dotsey and Mao (1993) develop alternative approaches to modeling the financing decision of the government. Each of these contributions specifies particular rules for retiring the debt, which may involve future increases in taxes or future cuts in government purchases. Both find that the form of the rule can have important effects on current responses to fiscal shocks. In the present context, we abstract from these interesting and potentially important effects, in order to focus on the direct effects of the policy shock alone.
} 
with contingent payouts, the country bears the entire wealth effect itself. In this case, private consumption falls immediately by the amount of the increase in government spending, in accordance with principle \#1 (see section 3). Investment, output, and the current account are unaffected by the shock.

Next, consider the response of a large economy with variable labor. Because of the country's size, the increase in government purchases will drive up the world interest rate, providing another channel by which the shock affects consumption and labor input (principles \#2 and \#4), consequently affecting investment and output as well. The complete markets model predicts that both countries increase labor effort and decrease consumption by the same amount, due to the complete risk-pooling and the fact that variations in government purchases have no direct incentive effects in the originating country. Consequently, the responses of investment and output are identical across countries.

Under incomplete markets, since the home country bears the entire wealth shock, the responses differ across countries, as plotted in Figure 8 . The negative wealth shock in the home country leads to an increase in labor input. The interest rate also rises in response to the shock (not plotted): this is a secondary force leading to an increase in labor input in the home country, and also explains the rise in foreign labor input. Output and investment rise in the home country, and remain permanently above the original steady state. Foreign output rises initially with the increase in foreign labor input, although foreign investment falls. The home country experiences current account and net export deficits on impact. In the new steady state, the foreign country holds a higher stock of claims on the home country, and finances part of its consumption from interest receipts. Thus the new steady state involves lower labor input and higher consumption in the foreign country, compared with the initial steady state. In the home country, by contrast, the new steady state is characterized by lower consumption and higher labor input. Finally, we note that in the large country case, there continues to be a predicted link between government spending, investment booms, and current account deficits.

\subsubsection{Temporary shocks}

Temporary variations in government purchases have potentially very different effects from permanent changes, since temporary changes offer much greater possibilities for intertemporal substitution. In particular, the more temporary is the shock, the smaller is the wealth effect and the larger are the substitution effects associated with changes in wage rates and interest rates. We illustrate these effects using the following stochastic process for temporary government spending shocks, where $\bar{G}$ is the average or "trend" level of purchases:

$$
G_{t}=\left(1-\rho_{G}\right) \bar{G}+\rho_{G} G_{t-1}+\varepsilon_{G t} .
$$

Table 3-A shows how the wealth effect and initial-period wage and interest rate effects of the one-unit increase in government purchases depend on the persistence of the 
shock to government purchases, $\rho_{G}$. Results are presented for the incomplete-markets economy only. Looking first at the wealth effect on consumption and labor input, we see that these are small until the shocks become very persistent, with $\rho_{G}$ greater than 0.95. The wealth effect is larger in magnitude under incomplete markets-about twice as large, since the economy in question represents half of world GDP - but the effect is nevertheless small unless the shock is very persistent. The relative importance of the wage and interest rate effects is therefore greater for shocks with lower persistence. Under both asset structures, the consumption response is dominated by the interest rate effect until the shock is extremely persistent. That is: the decline of consumption on impact is largely due to the effect of a temporary increase in the interest rate caused by the expansion of government purchases.

Turning next to the response of labor input, we find that both the interest rate and the wage rate are quantitatively important, but of opposite sign. The temporarily low real wage induces declines in labor input, while the temporary rise in the interest rate stimulates labor input. The two effects are predicted to be of roughly equal and opposite sign, so that they approximately cancel each other out. In the end, the response of labor input is roughly determined by the size of the wealth effect. Many economists are concerned that labor input may not respond to variations in intertemporal prices (interest rates) as predicted by this model. It is interesting to note, therefore, that-absent the interest rate effect-labor input would decline in response to government purchases shocks, since the wage effect dominates the wealth effect under either asset structure.

\subsection{Shocks to tax rates}

This section briefly considers the domestic and international implications of shocks to tax rates. Our model considers only a distorting tax on total output or, equivalently, identical taxes on capital and labor. ${ }^{29}$ To facilitate comparison of these experiments with the one-unit increase in the level of government purchases studied above, we consider a decrease in the distorting tax rate in an amount that would lead to a oneunit increase in the government fiscal deficit if there were no response of labor input. As before, we assume that the tax cut is financed by "Ricardian debt."

\subsubsection{Permanent shocks}

Figure 9 plots the incomplete-markets (bond) economy's response to this permanent, unanticipated, decline in the tax rate. This shock differs importantly from the government purchases shock studied earlier, since the decline in the tax rate generates a positive wealth effect, whereas the purchases shock led to a negative wealth effect. As with the government purchases shock, domestic labor input rises in response to

\footnotetext{
${ }^{29}$ For a more complete analysis of the open economy implications of a rich menu of tax shocks, both anticipated and unanticipated, see Arvanitis (1994).
} 
the shock. However, in the case of the tax cut, the increase in domestic labor input is due to a positive wage effect (the tax cut raises the marginal product of labor) combined with the interest rate effect (the interest rate rises with the tax cut). These two substitution effects are strong enough to overcome the wealth effect, which by itself would lead to a decrease in domestic labor input in response to the tax cut. Given the rise in labor input, domestic investment rises as well, as does domestic output. Domestic consumption also rises, because of the positive wealth effect of the shock.

In the foreign country, labor input initially rises due to the interest rate effect. Foreign output rises on impact, but falls over time. Investment falls in the foreign country, as capital owners locate new investment goods in the now-more-productive home country. The home country experiences initial current account and net export deficits, which improve over time. In the new steady state, as in the case of an increase in government purchases, the foreign country holds a larger stock of bonds, and finances part of its consumption from interest payments. However, the economic mechanisms leading to this shift in bond holdings differs importantly between the two experiments. In the case of a shock to government purchases, residents of the home country decumulate bonds to smooth their consumption path in response to the negative wealth shock. In the case of the permanent home country tax cut, the foreign country is permanently a lower-marginal-product place to work, and foreign residents find it advantageous (compared with the initial steady state) to support relatively more of their consumption from interest on debt, rather than by working.

\subsubsection{Temporary shocks}

Since the tax distorts private decisions, variations in the tax rate affect private incentives directly. Thus the analysis of tax shocks is more complicated than our earlier analysis of shocks to government purchases, which had only a direct wealth effect. Table 3-B summarizes the wealth and substitution effects on consumption of variations in tax rates of differing degrees of persistence, where we have assumed a stochastic process for taxes of the form:

$$
\tau_{t}=\left(1-\rho_{\tau}\right) \bar{\tau}+\rho_{\tau} \tau_{t-1}+\varepsilon_{\tau t} .
$$

As before, we only consider the incomplete markets economy. For both the consumption and labor responses, the wage effect is the dominant influence under both asset structures until the shock becomes very highly persistent. When the tax cut becomes close to permanent ( $\rho_{\tau}$ close to 1 ) the wealth effect begins to be important. Finally, we note that the sign of the interest rate effect depends on the degree of persistence of the tax shock-we provide an explanation for this phenomenon in section 7.3.2 below. 


\subsection{The twin deficits}

Many economists have noted an apparent link between fiscal deficits and current account deficits, with the link appearing especially strong since about the mid-1970's. At the same time, fiscal deficits are thought to crowd out private economic activity through increases in interest rates. This sub-section explores the model's implications for these phenomena.

\subsubsection{Government purchases}

Table 4-A shows the incomplete markets model's predictions for the effect of an unanticipated increase in government purchases on the current account deficit, interest rates, and the fiscal deficit in the bond economy. We assume here that the increase in purchases is financed on impact by an increase in debt as described above, so that the increase in purchases leads to an increase (on impact) in the fiscal deficit. This table shows that there is a robust relationship between the fiscal deficit and the current account deficit and, in particular, the impact effect of purchases shocks on the current account are largely insensitive to the persistence of the shock. ${ }^{30}$ The interest rate effect, on the other hand, is very sensitive to persistence. For purely temporary shocks $\left(\rho_{G}=0\right)$ the one-unit increase in purchases leads to an increase in interest rates of about 50 basis points. When the shock is permanent, the interest rate effect is negligible-only about 5 basis points.

This analysis suggests one potential reason why the large empirical literature on the relationship between fiscal deficits and interest rates has not found a robust relationship between fiscal deficits and interest rates. The effects are simply not very large when the variations in government purchases are highly persistent. One empirical study which does find a significant relationship is Barro's (1987) analysis of wartime experiences in Great Britain. Our analysis predicts that it should be exactly this type of large, temporary increase in purchases which would have the largest effect on world interest rates. Yi (1993) also finds that government purchases play a role in explaining recent U.S. net export deficits.

\subsubsection{Taxes}

As with government purchases, we investigate whether this model predicts a "twin deficits" phenomenon in response to decreases in distortionary taxation. Table 4-B shows the impact effect of the tax cut on the fiscal deficit, the trade deficit, and the interest rate for the bond economy. We note first that the sign of the interest rate effect depends on the persistence of the tax cut. For extremely short-lived tax cuts (low values of $\rho_{\tau}$ ) individuals would prefer to work harder while the tax cut is in effect,

\footnotetext{
${ }^{30} \mathrm{Ahmed}(1987)$ studies a related model but without variable labor; his model predicts that the current account effect should be larger for temporary shocks. He presents some empirical evidence to support this prediction.
} 
and smooth consumption over the infinite future by saving in the current period. The investment effect of a very short-lived tax cut is, however, expected to be minimal. In the extreme case of $\rho_{\tau}=0$, there is no direct incentive to alter investment since the tax cut will have disappeared by the time the new capital is in place. Hence, in order to balance saving and investment, the interest rate must fall to partially discourage saving. However, there is still a current account surplus as individuals purchase bonds from foreigners to partially smooth consumption in response to the temporary tax cut.

As the tax cut becomes more persistent, the intertemporal substitution effects associated with labor input become relatively less important and the investment effects become relatively more important. Once $\rho_{\tau}$ exceeds about 0.80 , the investment response is sufficiently strong that the interest rate must rise to equate world saving and world investment. As a consequence of the strong investment response, the home country experiences a current account deficit for very persistent decreases in the tax rate.

These results suggest an explanation for why empirical investigations of the "twin deficits" phenomenon have had mixed results. Our model predicts that temporary decreases in taxes should lead to current account surpluses, while more persistent tax cuts should lead to current account deficits. Empirical work which does not attempt to stratify the source of the fiscal deficit by separating government purchase shocks from tax shocks, and which does not separate permanent shocks from temporary shocks, is unlikely to uncover a robust relationship. A similar argument applies to empirical analyses of the relationship between deficits and interest rates-the model predicts very different effects depending on the source of the deficit shock and its persistence. In recent work, Kollman (1994) constructs a two-country real business cycle model, and finds that the model with incomplete markets can explain much of the recent variation in the U.S. trade balance, when driven by measured shocks to technology, taxes, and government purchases. ${ }^{31}$

\section{Multi-good models}

The single-good model, with its nine principles arising from intertemporal trade and the dynamics of capital accumulation, has taken us a long way toward understanding the transmission and propagation of business cycles across countries. Nevertheless, it is too limited a vehicle for addressing many questions at the heart of international trade and finance. This section summarizes the recent literature on multi-good models

\footnotetext{
${ }^{31}$ In related work, Devereux and Shi (1991) study the relationship between international debt and capital accumulation in a two-country model with endogenous time preference. They find that morepatient countries, or those with larger government sectors or lower productivity should be long-run creditors. They also find that it is possible for external asset accumulation to display 'overshooting' behavior.
} 
of international business cycles. These models have been generally developed to address two sets of questions left unanswered by the single-good model.

The first question concerns the behavior of the terms of trade and its relation to the trade balance and aggregate activity. While this linkage is likely important for understanding international business cycles, the single-good model obviously is silent on questions involving the terms of trade or the real exchange rate. Second, there is the "comovement problem:" the single-good model, when driven by empirically reasonable shock processes, cannot generate macro aggregates that exhibit the strong, positive, international comovement observed in the data. The comovement problem may be overcome in a multi-good setting with interdependencies in production and/or consumption. We summarize the literature on each of these questions in the following two sub-sections, and conclude with a discussion of other studies involving models with multiple goods.

\subsection{The terms of trade and the "J-curve"}

The relationship between the terms of trade and the balance of trade has long received a great deal of attention, both from policy makers, and also from academic economists. In particular, there is substantial interest in the so-called "J-curve" which describes a situation in which a deterioration in the terms of trade is associated with an initial worsening of the trade balance that subsequently improves (i.e., moves toward surplus). Early contributors to this literature include Junz and Rhomberg (1973) and Magee (1973); see also Meade (1988). More recently, Rose and Yellen (1989) use modern time-series methods to investigate whether a J-curve can be detected in the past 25 years of U.S. data. Their findings are quite negative: they find little statistical evidence of a stable J-curve in U.S. data.

On the theoretical side, a large literature has developed models that explored the conditions under which a deterioration in the terms of trade would lead to an improvement in the trade balance. ${ }^{32}$ Arvanitis and Mikkola (1994) and Backus, Kehoe, and Kydland (1994) have recently constructed two-good dynamic models of international trade which they use to explore the relationship between the terms of trade and the balance of trade. Figure 10 shows the cross-correlation functions for cyclic fluctuations in the terms of trade and net exports for eight countries. This figure shows that the contemporaneous correlation (lag 0 ) between net exports and the terms of trade is negative, but a rising correlation between the terms of trade and future net exports (i.e., the correlation rises with the lead, $k$ ). The correlation between the terms of trade and lagged net exports tends to be negative. It is this cross-correlation function, which Backus, et al. (1994) term the "S-curve," that the model will try to replicate. Note that the "S-curve", which is a description of unconditional cross-

\footnotetext{
${ }^{32}$ For a review of the early literature on the Harberger-Laursen-Metzler effect and a modern critique based on the intertemporal approach to the current account, see Persson and Svensson (1985).
} 
correlations between the two variables, is not the same thing as the "J-curve," which describes the conditional dynamic response of one variable following a shock to the other. Thus it is possible to find an "S-curve" in the data, even absent a detectable "J-curve."

Each of these investigations specifies the following structure for the world economy; this presentation draws heavily on that of Arvanitis and Mikkola (1994). There are two goods produced in a two-country world-one good is produced by each country. The goods are both tradable, and each good is used both as consumption and as investment in each country.

Preferences: Consumers in each country choose leisure, $L$, and consumption of the domestic good, $C_{x}$ and of the foreign good, $C_{y}$, to maximize expected lifetime utility. Thus, residents of the home country maximize

$$
E_{0} \sum_{t=0}^{\infty} \beta^{t} U\left(C_{x t}, C_{y t}, L_{t}\right)
$$

with momentary utility specialized to the following:

$$
U\left(C_{x t}, C_{y t}, L_{t}\right)=\frac{1}{1-\sigma}\left\{\left[\left(\eta_{c} C_{x t}^{-\mu}+\left(1-\eta_{c}\right) C_{y t}^{-\mu}\right)^{-1 / \mu}\right]^{\vartheta} L_{t}^{1-\vartheta}\right\}^{1-\sigma}
$$

Residents of the foreign country maximize

$$
E_{0} \sum_{t=0}^{\infty} \beta^{t} U\left(C_{x t}^{*}, C_{y t}^{*}, L_{t}^{*}\right)
$$

where momentary utility, $U($.$) , is given by:$

$$
U\left(C_{x t}^{*}, C_{y t}^{*}, L_{t}^{*}\right)=\frac{1}{1-\sigma}\left\{\left[\left(\left(1-\eta_{c}\right)\left(C_{x t}^{*}\right)^{-\mu}+\eta_{c}\left(C_{y t}^{*}\right)^{-\mu}\right)^{-1 / \mu}\right]^{\vartheta}\left(L_{t}^{*}\right)^{1-\vartheta}\right\}^{1-\sigma} .
$$

The two countries' utility functions are parameterized symmetrically: note each country prefers the consumption of its own good (the relative shares are governed by the parameter $\eta_{c}$, so a preference for one's own good means $\eta_{c}>0.50$ ). The elasticity of substitution between consumptions of the two goods is $\zeta \equiv(1+\mu)^{-1}$.

Production: Each country specializes in the production of a single good. The home country produces $X$ while the foreign country produces $Y$ : both production technologies use domestic labor together with domestic and foreign capital, as follows:

$$
X_{t}=A_{t}\left[\left(\eta_{p} K_{x t}^{-\mu}+\left(1-\eta_{p}\right) K_{y t}^{-\mu}\right)^{-1 / \mu}\right]^{1-\alpha}\left(X_{t} N\right)_{t}^{\alpha}
$$




$$
Y_{t}=A_{t}^{*}\left[\left(\left(1-\eta_{p}\right)\left(K_{x t}^{*}\right)^{-\mu}+\eta_{p}\left(K_{y t}^{*}\right)^{-\mu}\right)^{-1 / \mu}\right]^{1-\alpha}\left(X_{t}^{*} N_{t}^{*}\right)^{\alpha}
$$

where, as before, $X_{t}$ and $X_{t}^{*}$ capture deterministic trend growth in labor-augmenting technical change, and $A_{t}$ and $A_{t}^{*}$ represent total-factor-augmenting shocks to productivity, which are assumed to follow a vector-Markov process. Capital accumulation in the Arvanitis-Mikkola model is subject to small, convex costs of adjustment. Backus, et al., employ a time-to-build technology, but also explore a variant they call "timeto-ship."

Calibration: The model is calibrated in the standard way to replicate long-run shares, with curvature parameters taken from existing statistical studies. The Solow residual process is the one discussed earlier. As both sets of authors note, the results are extremely sensitive to the parameter $\zeta \equiv(1+\mu)^{-1}$, yet little is known about the value of this parameter. The benchmark value of $\zeta$ used by Backus, et al. (1994) is $\zeta=1.5$. The assumption that the critical parameter, $\mu$, is the same in both production and consumption permits a convenient aggregation of consumptions, investments, and government purchases, which they note is common in the computational-generalequilibrium trade literature; see for example, Whalley (1985).

Market structure: Backus, et al., (1994) assume that there are complete contingentclaim markets available to all individuals. Arvanitis and Mikkola (1994) also study the complete markets economy, as well as a case that allows international trade only in physical goods and a noncontingent real bond.

Results: Backus, et al. (1994) find that this model generates an "S-curve" for reasonable parameter values. In fact, the model also generates a "J-curve," in which the trade balance initially deteriorates following a positive productivity shock. That is: the positive productivity shock leads to a deterioration in the terms of trade, since the price of the domestic good falls. At the same time, the higher productivity draws capital from abroad, leading to a trade deficit. As the investment boom slows down and as domestic output and saving rise, the trade balance improves. Clearly, the dynamics of capital accumulation are central to the model's ability to generate the "J-curve" and also the "S-curve."

Backus, et al. (1994) provide a compelling illustration of the importance of capital by exhibiting the results for an economy with variable labor but without capital. In this case, consumption smoothing is the dominant force behind the trade balance, and the positive productivity shock leads to increased saving, i.e., a trade surplus. Neither a "J-curve" nor an "S-curve" is observed in this case. Further, neither effect is observed when the shock is to government spending, even with capital.

Although this model replicates the "S-curve" and possesses a "J-curve," the economic forces behind these effects are not those stressed in the older literature. That is: the "J-curve" does not arise because quantities of exports and imports are slow to 
adjust to terms-of-trade changes, although the relative price changes themselves are passed through relatively quickly. Rather, the "J-curve" is a consequence of the dynamics of capital accumulation. Finally, the two-good model does not deliver enough volatility in the terms of trade or in the trade balance. For the benchmark parameterization of Backus, et al. (1994), the volatility of net exports is about one-third that found in the data, while the model's predicted volatility for the terms of trade is about one-tenth that found in the data. Arvanitis and Mikkola (1994) experiment with allowing the elasticity of substitution in consumption to differ from that in production. The intuition is that a low elasticity of substitution in consumption will help produce volatility in the trade balance, while a high elasticity of substitution in production will help produce volatility in the terms of trade. They find that this alteration improves the model's predictions for volatility of the terms of trade and the trade balance, but that the model still falls short along this dimension.

Related literature: Praschnik (1993) studies a multi-sector model of a developing economy, and finds that relative price shocks are important for output volatility, but that productivity shocks are important for generating cyclic comovement of macroeconomic aggregates. Mendoza (1995) develops a three-sector model of a country facing a fixed world interest rate, and finds that terms-of-trade shocks account for a significant fraction of GDP variability, when the model is calibrated to mimic the G-7 countries. Macklem (1993) studies the relationship between terms-of-trade disturbances and fiscal policy in a small open economy calibrated to Canadian data. Schmitt-Grohe (1994) examines the extent to which the terms of trade transmit business cycles between the U.S. and Canada.

\subsection{Comovement}

In section 6.3.3 we described the "comovement problem" as one of the central problems with the one-good dynamic equilibrium trade model. The most widely-discussed feature of this problem is the consumption-output puzzle. There is a growing literature in which model variants are developed that successfully resolve this problem. A non-exhaustive list includes contributions by Devereaux, Gregory, and Smith (1992) which retains the complete-markets setup but alters the form of momentary utility; Reynolds (1992) which studies a two-good, two-country model similar to this one; and Stockman and Tesar (1990), who incorporate nontraded goods, but fail to resolve the consumption-output puzzle in the absence of preference shocks. In terms of the two-good model described above, the complete-markets version of the model continues to exhibit output correlations that are too low and consumption correlations are too high, with negative international correlation of labor inputs and investments. Arvanitis and Mikkola (1994) find that restricting asset trade to bonds alone helps to resolve this problem, if the productivity shocks are sufficiently persistent. Specifically, they generate output and consumption correlations that are both positive, but with 
the output correlation larger than the consumption correlations. These findings are consistent with results obtained by Baxter and Crucini (1993b), as well as the results from our benchmark case: see Table 2 .

However, there is another part of the puzzle, which is that all the models discussed so far tend to predict substantial, negative international comovement of labor inputs and investments so long as investment goods are traded internationally. Specifically, the two-good models of Arvanitis and Mikkola (1994), Backus, et al. (1994), and Reynolds $(1992,1993)$ all predict substantial, negative international correlations of investments and labor inputs, regardless of market structure. This is somewhat surprising, as these models incorporate international linkages on both the consumption and production side, so that there is a mechanism by which expansion of output in one country leads to a desire for more of the other country's good (as a complementary consumption good, or as complementary capital). Nevertheless, the overriding force behind investment dynamics in these two-good models is still the one that was at work in the one-good model. That is: investment flows to the more productive location, and labor input falls in the location with low investment.

\subsection{Other contributions}

In addition to the two topics reviewed above, there are several intriguing new developments in the general area of multi-good models. Canova and Dellas (1993) investigated whether trade interdependence could account for international comovement. Their results are mixed, and their overall conclusion is that the role of trade interdependencies in economic fluctuations is moderate. In related work, however, Costello and Praschnik (1993) study the interrelationships of macroeconomic aggregates across industrialized and developing economies. They find that output in the U.S. and Japan Granger-causes output in developing countries, and that variation in output in the U.S. and Japan accounts for a large fraction of the variation of output in developing countries.

Canova (1993) develops a three good, three country model characterized by complete markets. Each country produces only one good although production in each country requires output of all three countries as capital input. Further, individuals value consumption of all three goods. Canova studies several parametric cases in an effort to determine whether the common international component of national business cycles is due to common shocks or to transmission. He finds that production interdependencies determine the characteristics of the propagation of technology shocks, while consumption interdependencies are responsible for the transmission of government spending shocks. 


\section{New directions}

This chapter has summarized the large and growing literature on the quantitative equilibrium approach to modeling the dynamic interactions of trading economies. This approach has met with success in capturing many of the salient features of open economy business cycles, yet many puzzles remain. This section briefly outlines those areas in which new research is likely to be most productive.

Comovement: The standard, one-good model could not replicate the observed, strong positive international comovements in macroeconomic aggregates. It has proved particularly difficult to write down plausibly-parameterized models which can generate positive comovement of labor and investment across countries. The twogood models reviewed in section 8 did not fare better than the one-good model along this dimension. Thus a major challenge to the theory is to develop a model which can explain international comovement in labor input and investment. A natural direction to pursue is to incorporate intermediate goods in an effort to strengthen the intersectoral (and, thus, international) linkages on the supply side. Current work by Canova (1992), Costello and Praschnik (1993) and Kouparitsas (1994a) has made a start in this direction.

Volatility of net exports and the terms of trade: A second challenge to existing theory is the volatility of net exports and the terms of trade. The standard two-good model misses badly along this dimension, as it substantially underpredicts the volatility of these variables. Recent work by Kouparitsas (1994b) has found that the volatility both net exports is linked to the industrial structure of an economy, and in particular is linked to the composition of the traded goods. For example, countries whose export bases are not well-diversified, or in which exports are confined to highvolatility industries (such as primary materials) have more volatile business cycles and higher net export volatility. In a companion paper, Kouparitsas (1994c) finds that terms of trade volatility is also closely related to trade structure. In particular, he finds that countries in which the composition of exports differs importantly from the composition of imports also have highly volatile terms of trade. That is: he finds that terms of trade fluctuations mainly reflect movements in relative goods prices, rather than movements in relative country price levels or exchange rates. These findings suggest that models incorporating a richer industrial structure, with important roles for intermediate goods and the resulting intersectoral linkages, may be central to explaining the observed volatility of net exports and the terms of trade.

Measurement: As we develop richer models of intersectoral and international linkages, our data requirements will grow as well. It will become essential to have international data at the sectoral level for use in calibrating and estimating our models. 
Further work in assembling and interpreting sectoral international data is very desirable.

Applications: The modeling approach surveyed in this paper has developed to the point where these models have useful and important insights to offer in particular applied contexts. That is: it is feasible, and desirable, to construct particular versions of these models for application to particular countries or economic events. Canova (1993), for example, has constructed a three-region world which he has parameterized to correspond to the U.S., Germany, and Japan. His focus was on understanding the mechanisms by which various shocks are transmitted across countries.

Kouparitsas (1994a) constructs a two-region world, in which one region, the North, imports raw materials and exports manufactured goods. The second region, the South, exports raw materials and imports manufactures. The North is parameterized to resemble major industrialized countries, while the South is parameterized to correspond to non-oil, commodity-exporting, developing countries. Using this framework, Kouparitsas examines the extent to which fluctuations in the Northern economy cause fluctuations the terms of trade and induce business cycles in the Southern economy.

In conclusion, recent work in dynamic open economy macroeconomics has laid the foundations for studying the equilibrium relationship between international trade and business cycles. There is much more work to be done, as suggested above, with many exciting challenges ahead of us.

\section{References}

[1] Ahmed, S. "Government spending, the balance of trade, and the terms of trade in British history," Journal of Monetary Economics 20 (September 1987), 195-220.

[2] Arvanitis, Athansios V. (1994) Financial market linkages, fiscal policies, and international business cycles, Ph.D. dissertation, University of Rochester, 1994.

[3] Arvanitis, Athansios V. and Anne Mikkola (1994) "Asset market structure and international trade dynamics," manuscript, University of Rochester, April 1994.

[4] Aschauer, David (1989) "Is public expenditure productive?" Journal of Monetary Economics 23 (March 1989), 177-200.

[5] Atkeson, Andrew and Tamim Bayoumi (1991) "Do private capital markets insure against risk in a common currency area: Evidence from the US," manuscript, International Monetary Fund, 1991.

[6] Backus, David, Patrick Kehoe and Finn Kydland (1992a) "International real business cycles," Journal of Political Economy 101 (August 1992), 745-775. 
[7] Backus, David and Patrick Kehoe (1992b) "International evidence on the historical properties of business cycles," American Economic Review 82 (September 1992), 864-888.

[8] Backus, David, Patrick Kehoe and Finn Kydland (1994) "Dynamics of the trade balance and the terms of trade: The J-curve," American Economic Review 1994.

[9] Barro, Robert J. (1987) "Government Spending, Interest Rates, Prices, and Budget Deficits in the United Kingdom, 1701-1918," Journal of Monetary Economics 20, (September 1987), 221-248.

[10] Baxter, Marianne (1991) "Approximating suboptimal dynamic equilibria: An Euler equation approach," Journal of Monetary Economics 27 (October 1991), 173-200.

[11] Baxter, Marianne (1993) "Financial market linkages and the international transmission of fiscal policy," manuscript, University of Virginia, 1993.

[12] Baxter, Marianne and Mario J. Crucini (1993a) "Explaining saving-investment correlations," American Economic Review 83 (June1993), 416-436.

[13] Baxter, Marianne and Mario J. Crucini (1993b) "Business cycles and the asset structure of foreign trade," manuscript, University of Virginia, 1993, and forthcoming, International Economic Review, November 1995.

[14] Baxter, Marianne and Robert G. King (1993) "Fiscal policy in general equilibrium," American Economic Review 83 (June 1993), 315-334.

[15] Baxter, Marianne and Robert G. King (1994) "Measuring business cycles: Approximate band-pass filters for economic time series," manuscript, University of Virginia, June 1993.

[16] Blackburn, Keith and Morten P. Ravn (1991) "Contemporary macroeconomic fluctuations: An international perspective," manuscript, January 1991.

[17] Blackburn, Keith and Morten P. Ravn (1992) "Business cycles in the U.K.: Facts and fictions, Economica 59 (November 1992), 383-401.

[18] Brandner, Peter and Klaus Neusser (1992) "Business cycles in open economies: Stylized facts for Austria and Germany," Weltwirtschaftliches Archiv 128 (March 1992), 67-87.

[19] Burda, Michael C. and Stefan Gerlach (1992) "Intertemporal prices and the U.S. trade balance," American Economic Review 82:5 (December 1992) 1234-1253.

[20] Burns, Arthur M. and Wesley C. Mitchell (1946), Measuring Business Cycles, New York, N.Y.: National Bureau of Economic Research, 1946. 
[21] Canova, Fabio (1992) "Sources and propagation of international business cycles: Common shocks or transmission?" manuscript, European University Institute, October 1992.

[22] Canova, Fabio and Harris Dellas (1993) "Trade interdependence and the international business cycle," Journal of International Economics 34:23-47.

[23] Cantor, Richard and Nelson Mark (1987) "International debt and world business fluctuations," Journal of International Money and Finance 6:153-165.

[24] Cantor, Richard and Nelson Mark (1988) "The international transmission of real business cycles," International Economic Review 29: 493-507.

[25] Cardia, Emanuela (1991) "The dynamics of a small open economy in response to monetary, fiscal, and productivity shocks," Journal of Monetary Economics 28 (December 1991), 411-434.

[26] Christiano, Lawrence and Martin Eichenbaum (1992) "Current real-businesscycle theories and aggregate labor-market fluctuations," American Economic Review 82 (June 1992) 430-450.

[27] Conze, Antoine, Jean-Michel Lasry, and Jose Scheinkman (1990) "Borrowing constraints and international comovements," manuscript, University of Chicago, September 1990.

[28] Correia, Isabel; Joao Neves and Sergio Rebelo (1992) "Business cycles in Portugal: Theory and evidence," in: Amaral, Lucena, and Mello (eds.), Portugal toward 1992, Kluwer Academic Publishers, 1992.

[29] Correia, Isabel; Joao Neves and Sergio Rebelo (1994) "Business cycles in a small open economy," forthcoming, European Economic Review.

[30] Costello, Donna M. (1993) "A cross-country, cross-industry comparison of productivity growth," Journal of Political Economy 101, 207-222.

[31] Costello, Donna M. and Jack Praschnik (1993) "Intermediate goods and the transmission of international business cycles," manuscript, University of Western Ontario, March 1993.

[32] Crucini, Mario J. (1993a) "Country size and economic fluctuations," manuscript, Ohio State University, 1993.

[33] Crucini, Mario J. (1993) "International risk-sharing: A simple comparative test," manuscript, Ohio State University, 1993.

[34] Dellas, Harris (1986) "A real model of the world business cycle," Journal of International Money and Finance 5:381-394. 
[35] Devereux, Michael B. and Shouhong Shi (1991) "Capital accumulation and the current account in a two-country model," Journal of International Economics 30:1/2, (February 1991), 1-25.

[36] Devereux, Michael B., Allan Gregory and Gregor Smith, (1992) "Realistic crosscountry consumption correlations in a two-country, equilibrium, business-cycle model," Journal of International Money and Finance (January 1992).

[37] Dotsey, Michael and Ching-Sheng Mao (1992) "How well do approximation methods work?" Journal of Monetary Economics 29:25-58.

[38] Dotsey, Michael and Ching-Sheng Mao (1994) "The effects of fiscal policies in the neoclassical growth model," Working Paper \#94-3, Federal Reserve Bank of Richmond, February 1994.

[39] Engel, Charles and Kenneth Kletzer (1989) "Saving and investment in an open economy with non-traded goods," International Economic Review 30:4 (November 1989), 735-752.

[40] Englund, Peter, Torsten Persson, and Lars Svensson (1990) "Swedish business cycles: 1861-1988," manuscript, Stockholm University, September 1990.

[41] Finn, Mary (1990) "On savings and investment dynamics in a small open economy," Journal of International Economics 29 (1990), 1-21.

[42] Frenkel, Jacob and Assaf Razin (1987) Fiscal policies and the world economy: An intertemporal approach, Cambridge, MA: MIT Press.

[43] Gaudin, Sylvestre and Kei-Mu Yi (1993 "The role of real interest rates in explaining trade balance movements in small open economies," manuscript, Rice University, November 1993.

[44] Glick, Reuven and Kenneth Rogoff (1994) "Global versus country-specific productivity shocks and the current account," international Finance Discussion Paper 443, Board of Governors of the Federal Reserve System, and forthcoming, Journal of Monetary Economics.

[45] Hall, Robert (1978) "Stochastic implications of the life cycle-permanent income hypothesis: Theory and evidence," Journal of Political Economy 86:971-987.

[46] Hayashi, F. (1982) "Tobin's marginal q and average q: A neoclassical interpretation," Econometrica vol, 213-224.

[47] Head, Allen (1992) "Country size, international risk sharing, and business cycles: Theory and evidence, manuscript, Queen's University, March 1992.

[48] Hicks, John P. (1939) Value and Capital, Oxford: Oxford University Press. 
[49] Hodrick, Robert and Edward Prescott (1980) "Post-war U.S. business cycles: An empirical investigation," manuscript, Carnegie Mellon University, November 1980.

[50] Judd, Kenneth (1990) "Minimum weighted residual methods for solving dynamic economic models," manuscript, Hoover Institution, July 1990.

[51] Junz, Helen and Rudolf Rhomberg (1973) "Price competitiveness in export trade among industrial countries," American Economic Review 63 (May 1973), 412418.

[52] Kim, Kunhong, R.A. Buckle and V.B. Hall (1992) "Key features of New Zealand business cycles," manuscript, Victoria University of Wellington, 1992; and forthcoming, Economic Record.

[53] King, Robert G. (1990) "Value and capital in the equilibrium business cycle program," in: Value and capital: Fifty years later," L. McKenzie and S. Zamagni, eds., London: MacMillan (1990).

[54] King, Robert G. (1994) "Quantitative theory and econometrics," forthcoming, Economic Review, Federal Reserve Bank of Richmond.

[55] King, Robert G., Charles I. Plosser and Sergio T. Rebelo (1987) "Technical Appendix to: 'Production, growth, and business cycles"', working paper, Rochester Center for Economic Research.

[56] King, Robert G., Charles I. Plosser and Sergio T. Rebelo (1988) "Production, growth, and business cycles I: The basic neoclassical model," Journal of Monetary Economics 21 (month 1988), 195-232.

[57] King, Robert G. and Sergio T. Rebelo (1993) "Low frequency filtering and real business cycles," Journal of Economic Dynamics and Control 17, 207-231.

[58] Kollman, Robert (1992) "Incomplete asset markets and international real business cycles," manuscript, University of Montreal, 1992.

[59] Kollman, Robert (1993) "Fiscal policy, technology shocks, and the US trade balance deficit," manuscript, University of Montreal, April 1993.

[60] Kouparitsas, Michael (1994a) "North-South business cycles," manuscript, University of Virginia, September 1994.

[61] Kouparitsas, Michael (1994b) "The relationship between business cycle volatility and export diversification," manuscript, University of Virginia, September 1994.

[62] Kouparitsas, Michael (1994c) "Relative prices and the terms of trade," manuscript, University of Virginia, September 1994. 
[63] Kydland, Finn and Edward Prescott (1982) "Time to build and aggregate fluctuations," Econometrica 50 (November 1982), 1345-1370.

[64] Leiderman, Leonardo and Assaf Razin (1991) "Determinants of external imbalances: The role of taxes, government spending, and productivity," Journal of the Japanese and International Economies 5:4 (December 1991), 421-450.

[65] Lewis, Karen K. (1993) "What can explain the apparent lack of international consumption risk sharing?" manuscript, Wharton School of the University of Pennsylvania, June 1993.

[66] Long, John and Charles Plosser (1983) "Real business cycles," Journal of Political Economy 91:1345-1370.

[67] Macklem, R. Tiff (1993) "Terms-of-trade disturbances and fiscal policy in a small open economy," Economic Journal 103:419 (July 1993), 916-936.

[68] Magee, Stephen (1973) "Currency contracts, pass-through, and devaluation," Brookings Papers on Economic Activity 1 (1973), 303-323.

[69] Meade, Ellen (1988) "Exchange rates, adjustment, and the J-curve," Federal Reserve Bulletin 74 (1988), 633-644.

[70] Mendoza, Enrique G. (1991) "Real business cycles in a small open economy," American Economic Review 81, 797-818.

[71] Mendoza, Enrique G. (1995) "The terms of trade, the real exchange rate, and economic fluctuations," forthcoming, International Economic Review (February 1995).

[72] Obstfeld, Maurice (1986) "Capital mobility in the world economy: Theory and measurement," Carnegie-Rochester Conference Series on Public Policy 24: 55103.

[73] Obstfeld, Maurice and Kenneth Rogoff (1995) "The intertemporal approach to the current account," in: Handbook of international economics, Gene Grossman and Kenneth Rogoff (eds), Amsterdam: North-Holland, 1995.

[74] Penati, Alessandro and Michael Dooley (1984) "Current account imbalances and capital formation in industrial countries, 1949-1981, IMF Staff Papers 31, 1-24.

[75] Persson, Torsten and Lars Svensson (1985) "Current account dynamics and the terms of trade: Harberger-Laursen-Metzler two generations later," Journal of Political Economy 93:1 (1985), 43-65. 
[76] Praschnik, Jack (1993) "The importance of input price shocks for business cycles in developing economies," manuscript, University of Western Ontario, January 1993.

[77] Prescott, Edward "Theory ahead of business-cycle measurement," CarnegieRochester Conference Series on Public Policy 24 (Autumn1986), 11-44.

[78] Rebelo, Sergio T. (1987) "Tractable heterogeneity and near-steady-state dynamics," manuscript, Northwestern University, 1987.

[79] Razin, Assaf (1993) "The dynamic-optimizing approach to the current account: Theory and evidence," Working Paper 4334, National Bureau of Economic Research, April 1993.

[80] Reynolds, Patricia (1992) "International comovements in production and consumption: Theory and evidence," manuscript, University of Southern California, November 1992.

[81] Reynolds, Patricia (1993) "International comovements in aggregate productivity: An empirical analysis," manuscript, University of Southern California, December 1993.

[82] Rogoff, Kenneth (1992) "Traded goods consumption smoothing and the random walk behavior of the real exchange rate," Bank of Japan Monetary and Economic Studies 10:1-29.

[83] Rose, Andrew and Janet Yellen (1989) "Is there a J-curve?" Journal of Monetary Economics 24:1 (July 1989), 53-68.

[84] Sachs, Jeffrey D. (1981) "The current account and macroeconomic adjustment in the 1970's," Brooking papers on economic activity, 201-268.

[85] Sadka, Joyce and Kei-Mu Yi (1994) "Consumer durables, permanent terms of trade shocks, and the recent U.S. trade deficits," manuscript, Rice University, June 1994 .

[86] Schmitt-Grohe, Stephanie (1994) "The international transmission of economic fluctuations: Effects of U.S. business cycles on the Canadian economy," manuscript, University of Chicago, 1994.

[87] Sen, Partha and S. Turnovsky (1990) "Investment tax credit in an open economy," Journal of Public Economics 42 (1990), 277-299.

[88] Stockman, Alan C. and Lars E.O. Svensson (1987) "Capital flows, investment, and exchange rates," Journal of Monetary Economics 19 (1987), 171-201. 
[89] Stockman, Alan C. and Linda L. Tesar (1990) "Tastes and technology in a twocountry model of the business cycle: Explaining international comovements," Working paper 3566, National Bureau of Economic Research, and forthcoming, American Economic Review.

[90] Taylor, John and Harald Uhlig (1990) "Solving nonlinear stochastic growth models: A comparison of alternative solution methods," Journal of Business and Economic Statistics 8, 1-18.

[91] Tesar, Linda L. (1991) "Savings, investment, and international capital flows," Journal of International Economics 31, 55-78.

[92] Whalley, John (1985) Trade liberalization among major trading areas, Cambridge, MA: MIT Press, 1985.

[93] van Wincoop, Eric (1992a) "International risk-sharing," manuscript, Boston University, November 1992.

[94] van Wincoop, Eric (1992b) "Regional risk-sharing," manuscript, Boston University, November 1992.

[95] van Wincoop, Eric (1993) "Real interest rates in a global bond economy," manuscript, IGIER, Milan, Italy, April 1993.

[96] Yi, Kei-Mu (1993) "Can government purchases explain recent U.S. net export deficits?" Journal of International Economics 35 (1993), 201-255.

[97] Zimmerman, Christian (1991) "International real business cycles among large and small countries," manuscript, Carnegie Mellon University, December 1991. 
TABLE 1: Business cycles in 10 OECD countries

\section{A. Volatility (\% per quarter)}

\begin{tabular}{|c|c|c|c|c|c|c|c|c|c|c|}
\hline & us & Australia & Austria & Canada & France & Germany & Italy & Japan & Switzerland & UK \\
\hline output & 2.00 & 1.48 & 1.26 & 1.60 & 0.96 & 1.46 & 1.80 & 1.32 & 2.06 & 1.56 \\
\hline consumption & 1.43 & 0.87 & 1.18 & 1.37 & 0.92 & 1.12 & 1.41 & 1.45 & 1.33 & 1.78 \\
\hline investment & 6.70 & 4.06 & 3.05 & 4.45 & 2.83 & 3.61 & 3.59 & 3.37 & 4.20 & 3.66 \\
\hline employment & 1.24 & 0.51 & 1.65 & 1.39 & 0.56 & 0.94 & 0.55 & 0.47 & 1.40 & 1.19 \\
\hline gov't purchases & 1.36 & 1.38 & 0.47 & 0.88 & 0.67 & 1.00 & 0.41 & 0.82 & 0.81 & 0.98 \\
\hline net exports & 0.51 & 1.23 & 0.99 & 0.75 & 0.85 & 0.82 & 1.45 & 0.93 & 1.47 & 1.16 \\
\hline
\end{tabular}

\section{B. Volatility relative to own-country output}

\begin{tabular}{|c|c|c|c|c|c|c|c|c|c|c|}
\hline & US & Australia & Austria & Canada & France & Germany & Italy & Japan & Switzerland & UK \\
\hline output & 1.00 & 1.00 & 1.00 & 1.00 & 1.00 & 1.00 & 1.00 & 1.00 & 1.00 & 1.00 \\
\hline consumption & 0.71 & 0.59 & 0.94 & 0.86 & 0.95 & 0.77 & 0.78 & 1.10 & 0.65 & 1.14 \\
\hline investment & 3.35 & 2.75 & 2.43 & 2.78 & 2.94 & 2.48 & 1.99 & 2.56 & 2.04 & 2.35 \\
\hline employment & 0.62 & 0.34 & 1.31 & 0.87 & 0.58 & 0.64 & 0.31 & 0.36 & 0.68 & 0.77 \\
\hline gov't purchases & 0.68 & 0.93 & 0.38 & 0.55 & 0.70 & 0.69 & 0.23 & 0.62 & 0.39 & 0.63 \\
\hline net exports & 0.25 & 0.83 & 0.78 & 0.47 & 0.88 & 0.56 & 0.80 & 0.71 & 0.72 & 0.74 \\
\hline
\end{tabular}


TABLE 1, cont'd.

C. Correlation with own-country output

\begin{tabular}{|c|c|c|c|c|c|c|c|c|c|c|}
\hline & US & Australia & Austria & Canada & France & Germany & Italy & Japan & Switzerland & UK \\
\hline output & 1.00 & 1.00 & 1.00 & 1.00 & 1.00 & 1.00 & 1.00 & 1.00 & 1.00 & 1.00 \\
\hline consumption & 0.82 & 0.61 & 0.74 & 0.88 & 0.67 & 0.69 & 0.86 & 0.79 & 0.85 & 0.85 \\
\hline investment & 0.97 & 0.79 & 0.79 & 0.57 & 0.83 & 0.88 & 0.86 & 0.93 & 0.84 & 0.68 \\
\hline employment & 0.91 & 0.09 & 0.62 & 0.75 & 0.90 & 0.63 & 0.54 & 0.80 & 0.84 & 0.54 \\
\hline gov't purchases & 0.01 & 0.22 & -0.36 & -0.32 & 0.18 & 0.17 & 0.21 & -0.12 & 0.16 & 0.04 \\
\hline net exports & -0.37 & -0.05 & -0.63 & -0.35 & -0.33 & -0.21 & -0.73 & -0.32 & -0.66 & -0.40 \\
\hline
\end{tabular}

D. Cross-correlation with same U.S. variable

\begin{tabular}{|l|r|r|r|r|r|r|r|r|r|r|}
\hline & \multicolumn{1}{|c|}{ US } & \multicolumn{1}{c|}{ Australia } & \multicolumn{1}{c|}{ Austria } & \multicolumn{1}{c|}{ Canada } & \multicolumn{1}{c|}{ France } & \multicolumn{1}{l|}{ Germany } & \multicolumn{1}{c|}{ Italy } & Japan & Switzerland & \multicolumn{1}{c|}{ UK } \\
\hline output & 1.00 & 0.60 & 0.54 & 0.81 & 0.46 & 0.85 & 0.49 & 0.66 & 0.48 & 0.64 \\
\hline consumption & 1.00 & -0.13 & 0.45 & 0.46 & 0.42 & 0.64 & 0.04 & 0.49 & 0.48 & 0.42 \\
\hline investment & 1.00 & 0.21 & 0.57 & 0.00 & 0.22 & 0.66 & 0.39 & 0.59 & 0.38 & 0.46 \\
\hline employment & 1.00 & -0.17 & 0.58 & 0.50 & 0.36 & 0.60 & 0.11 & 0.48 & 0.43 & 0.68 \\
\hline gov't purchases & 1.00 & 0.46 & 0.31 & 0.08 & -0.18 & 0.40 & 0.23 & 0.06 & -0.01 & -0.10 \\
\hline net exports & 1.00 & 0.03 & 0.29 & -0.10 & -0.25 & -0.23 & -0.28 & -0.59 & -0.10 & -0.11 \\
\hline
\end{tabular}

Data source: OECD and IMF, provided by David Backus; sample period is 1970:1-1990:1. All variables except net exports are in logarithms; all variables filtered with the $\mathrm{BP}_{12}(6,32)$ approximate band-pass filter described in Baxter and King (1994). 
TABLE 2: Model predictions

A. Benchmark case: Trend-stationary shocks with correlated innovations

\begin{tabular}{|c|c|c|c|c|c|c|c|c|c|c|c|}
\hline & \multicolumn{2}{|c|}{$\begin{array}{l}\text { Standard } \\
\text { deviation }\end{array}$} & \multicolumn{2}{|c|}{$\begin{array}{l}\text { Relative } \\
\text { std. dev. }\end{array}$} & \multicolumn{2}{|c|}{ Persistence } & \multicolumn{2}{|c|}{$\begin{array}{c}\text { corr w/output, } \\
\operatorname{lag} 0 \\
\end{array}$} & & \multicolumn{2}{|c|}{$\begin{array}{c}\text { Other } \\
\text { Correlations } \\
\end{array}$} \\
\hline & $\mathrm{CM}$ & IM & $\mathrm{CM}(1)$ & IM & $\mathrm{CM}$ & IM & $\mathrm{CM}$ & IM & & $\mathrm{CM}$ & $\mathrm{IM}$ \\
\hline output & 1.69 & 1.04 & 1.00 & 1.00 & 0.93 & 0.92 & 1.00 & 1.00 & $y, y^{*}$ & -0.55 & 0.20 \\
\hline consumption & 0.79 & 1.06 & 0.47 & 1.02 & 0.91 & 0.90 & 0.48 & 0.94 & $c, c^{*}$ & 1.00 & 0.11 \\
\hline investment & 9.14 & 4.09 & 5.41 & 3.93 & 0.90 & 0.90 & 0.73 & 0.76 & $\mathrm{i}, \mathrm{i}^{*}$ & -0.93 & -0.67 \\
\hline labor & 1.19 & 0.30 & 0.70 & 0.29 & 0.94 & 0.94 & 0.88 & 0.13 & $\mathrm{~N}, \mathrm{~N}^{*}$ & -0.99 & -0.92 \\
\hline net exports & 1.23 & 0.76 & 0.73 & 0.73 & 0.94 & 0.91 & 0.06 & -0.25 & $\mathrm{~s}, \mathrm{i}$ & 0.76 & 0.45 \\
\hline
\end{tabular}

CM: results for complete markets economy; IM: results for economy trading noncontingent bonds and goods only. Parameterization of this case is: $\rho=\rho^{*}=0.995$, $v^{*} \mathrm{v}^{*}=0, \operatorname{corr}\left(\varepsilon, \varepsilon^{*}\right)=0.258, \operatorname{var}(\varepsilon)=\operatorname{var}\left(\varepsilon^{*}\right)=0.73$.

\section{B. Trend-stationary shocks with large spillovers: The BKK parameterization}

\begin{tabular}{|c|c|c|c|c|c|c|c|c|c|c|c|}
\hline & $\mathrm{CM}$ & IM & $\mathrm{CM}(1)$ & $\mathrm{IM}$ & $\mathrm{CM}$ & IM & $\mathrm{CM}$ & $\mathrm{IM}$ & & $\mathrm{CM}$ & IM \\
\hline consumption & 0.78 & 0.78 & 0.59 & 0.60 & 0.91 & 0.91 & 0.61 & 0.65 & $c, c^{*}$ & 1.00 & 1.00 \\
\hline investment & 2.68 & 2.52 & 2.02 & 1.93 & 0.89 & 0.89 & 0.98 & 0.97 & $\mathrm{i}, \mathrm{i}^{*}$ & -0.20 & -0.10 \\
\hline net exports & 0.64 & 0.64 & 0.48 & 0.49 & 0.89 & 0.89 & 0.78 & 0.78 & $\mathrm{~s}, \mathrm{i}$ & 0.92 & 0.90 \\
\hline
\end{tabular}

CM: results for complete markets economy; IM: results for economy trading noncontingent bonds and goods only. Parameterization of this case is: $\rho=\rho^{*}=0.906$, $\nu=\nu^{*}=0.088, \operatorname{corr}\left(\varepsilon, \varepsilon^{*}\right)=0.258, \operatorname{var}(\varepsilon)=\operatorname{var}\left(\varepsilon^{*}\right)=0.73$. 
TABLE 3: Wealth and substitution effects of fiscal shocks

\section{A. Increase in government purchases}

\begin{tabular}{|c|c|c|c|c|c|c|c|c|}
\hline \multirow[b]{2}{*}{$\rho_{\mathrm{g}}$} & \multicolumn{4}{|c|}{ consumption response (goods units) } & \multicolumn{4}{|c|}{ labor response (per cent) } \\
\hline & total & wealth & interest rate & wage rate & total & wealth & interest rate & wage rate \\
\hline 0 & -0.0787 & -0.0028 & -0.073 & -0.0028 & 0.1979 & 0.0188 & 0.4925 & -0.3134 \\
\hline 0.4 & -0.088 & -0.0046 & -0.0789 & -0.0045 & 0.2213 & 0.0308 & 0.5321 & -0.3416 \\
\hline 0.8 & -0.1248 & -0.0127 & -0.1012 & -0.0109 & 0.3140 & 0.0856 & 0.6825 & -0.4540 \\
\hline 0.95 & -0.2046 & -0.0399 & -0.1412 & -0.0236 & 0.5148 & 0.2690 & 0.9517 & -0.7060 \\
\hline 0.975 & -0.2474 & -0.0642 & -0.1542 & -0.0291 & 0.6224 & 0.4325 & 1.0397 & -0.8498 \\
\hline 1 & -0.3620 & -0.1827 & -0.1827 & -0.0366 & 0.9107 & 1.2318 & 0.9623 & -1.2833 \\
\hline
\end{tabular}

\section{B. Decrease in tax rate}

\begin{tabular}{|c|c|c|c|c|c|c|c|c|}
\hline \multirow[b]{2}{*}{$\rho_{\tau}$} & \multicolumn{4}{|c|}{ consumption response (goods units) } & \multicolumn{4}{|c|}{ labor response (per cent) } \\
\hline & total & wealth & interest rate & wage rate & total & wealth & interest rate & wage rate \\
\hline 0 & 0.0610 & 0.0002 & 0.0111 & 0.0497 & 0.4861 & -0.0015 & -0.0747 & 0.5623 \\
\hline 0.4 & 0.0609 & 0.0004 & 0.0101 & 0.0504 & 0.4865 & -0.0026 & -0.0682 & 0.5572 \\
\hline 0.8 & 0.0614 & 0.0014 & 0.0057 & 0.0543 & 0.4852 & -0.0096 & -0.0383 & 0.5331 \\
\hline 0.95 & 0.0720 & 0.0069 & -0.0089 & 0.0740 & 0.4586 & -0.0464 & 0.0599 & 0.4452 \\
\hline 0.975 & 0.0873 & 0.0130 & -0.0216 & 0.0958 & 0.4201 & -0.0880 & 0.1457 & 0.3624 \\
\hline 1 & 0.1817 & 0.0475 & -0.0828 & 0.2171 & 0.1825 & -0.3199 & 0.5580 & -0.0556 \\
\hline
\end{tabular}


TABLE 4: International effects of fiscal shocks

A. Impact effect of one-unit increase in government purchases

\begin{tabular}{||c||c|c|c|c||}
\hline rhog & $\begin{array}{c}\text { fiscal } \\
\text { deficit }\end{array}$ & $\begin{array}{c}\text { trade } \\
\text { deficit }\end{array}$ & $\begin{array}{c}\text { CA } \\
\text { deficit }\end{array}$ & $\begin{array}{c}\text { interest } \\
\text { rate* }\end{array}$ \\
\hline \hline 0.000 & 0.97 & 0.50 & 0.51 & 47.5 \\
0.200 & 0.97 & 0.50 & 0.51 & 38.0 \\
0.400 & 0.97 & 0.50 & 0.51 & 28.5 \\
0.600 & 0.96 & 0.50 & 0.51 & 19.2 \\
0.800 & 0.95 & 0.50 & 0.51 & 10.2 \\
0.900 & 0.94 & 0.50 & 0.50 & 6.3 \\
0.950 & 0.92 & 0.50 & 0.50 & 5.0 \\
0.975 & 0.90 & 0.49 & 0.50 & 4.7 \\
1.000 & 0.84 & 0.48 & 0.49 & 5.1 \\
\hline
\end{tabular}

B. Impact effect of decrease in tax rate (one-unit decline in revenue)

\begin{tabular}{||c||c|c|c|c||}
\hline rhot & $\begin{array}{c}\text { fiscal } \\
\text { deficit }\end{array}$ & $\begin{array}{c}\text { trade } \\
\text { deficit }\end{array}$ & $\begin{array}{c}\text { CA } \\
\text { deficit }\end{array}$ & $\begin{array}{c}\text { interest } \\
\text { rate* }\end{array}$ \\
\hline \hline 0.000 & 0.92 & -0.13 & -0.13 & -12.4 \\
0.200 & 0.92 & -0.12 & -0.12 & -9.0 \\
0.400 & 0.92 & -0.10 & -0.10 & -5.5 \\
0.600 & 0.92 & -0.07 & -0.07 & -2.1 \\
0.800 & 0.92 & 0.00 & 0.00 & 1.3 \\
0.900 & 0.92 & 0.10 & 0.11 & 3.1 \\
0.950 & 0.92 & 0.21 & 0.22 & 4.0 \\
0.975 & 0.93 & 0.31 & 0.31 & 4.5 \\
1.000 & 0.97 & 0.47 & 0.48 & 5.0 \\
\hline
\end{tabular}

* annualized basis points. 
Figure 1

USA: current account and net exports

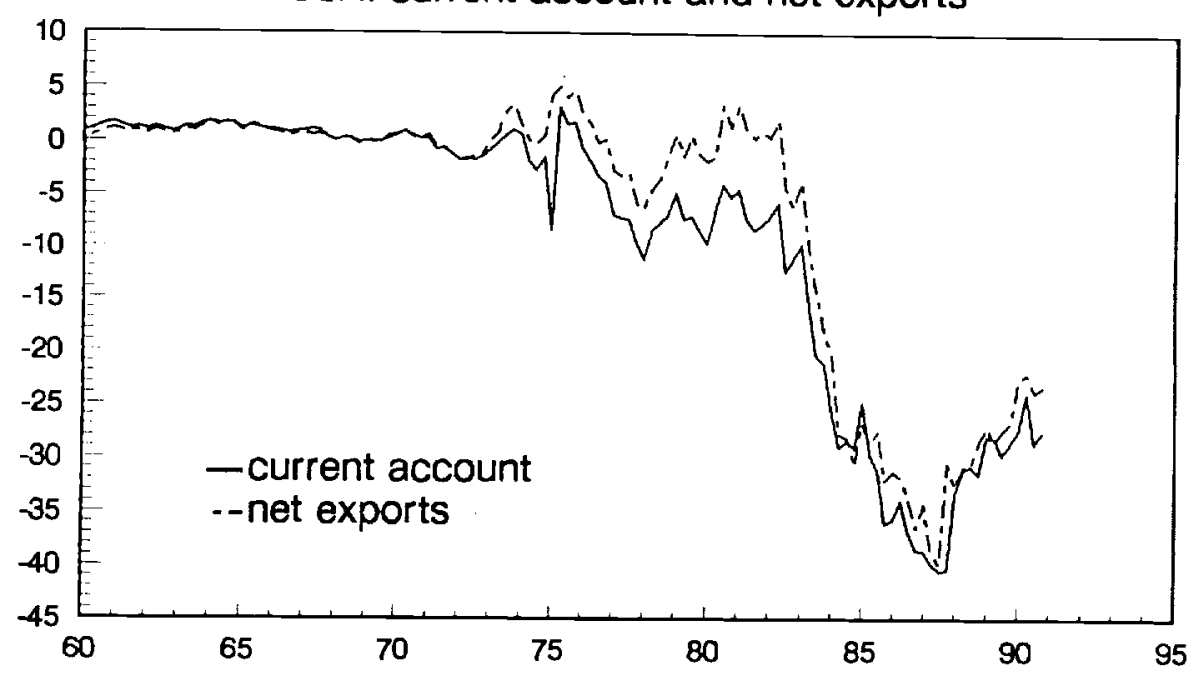

USA: cyclic components of CA and NX

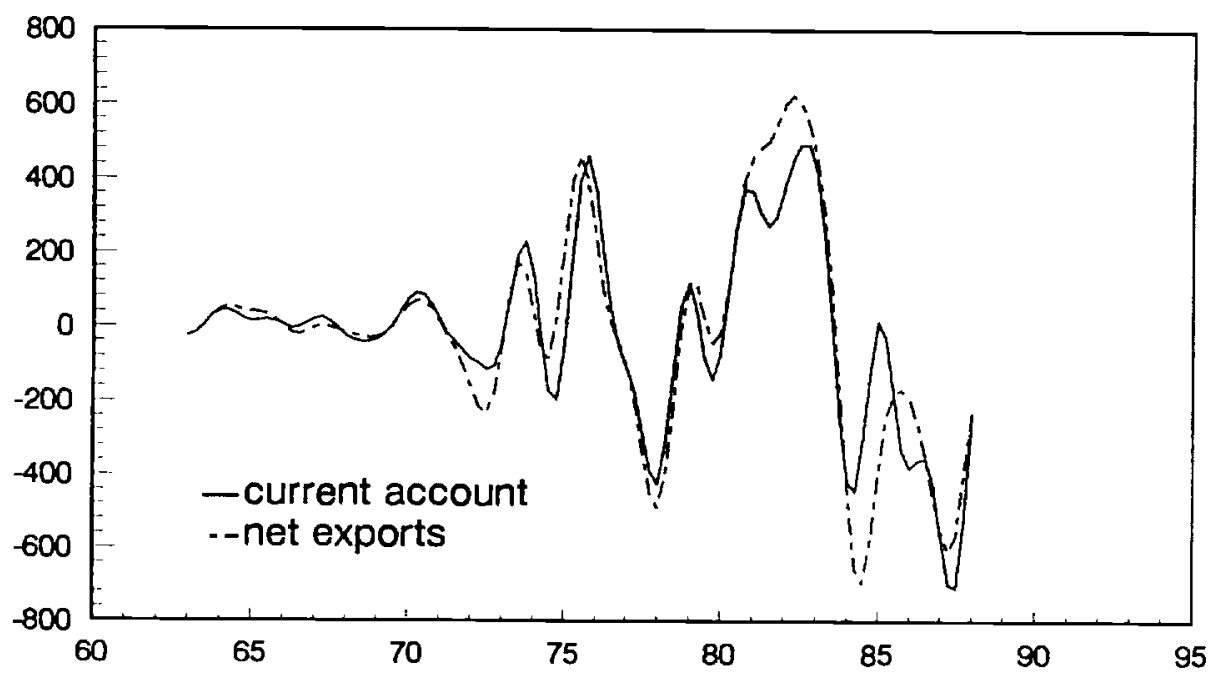


Figure 2: The composition of exports and imports
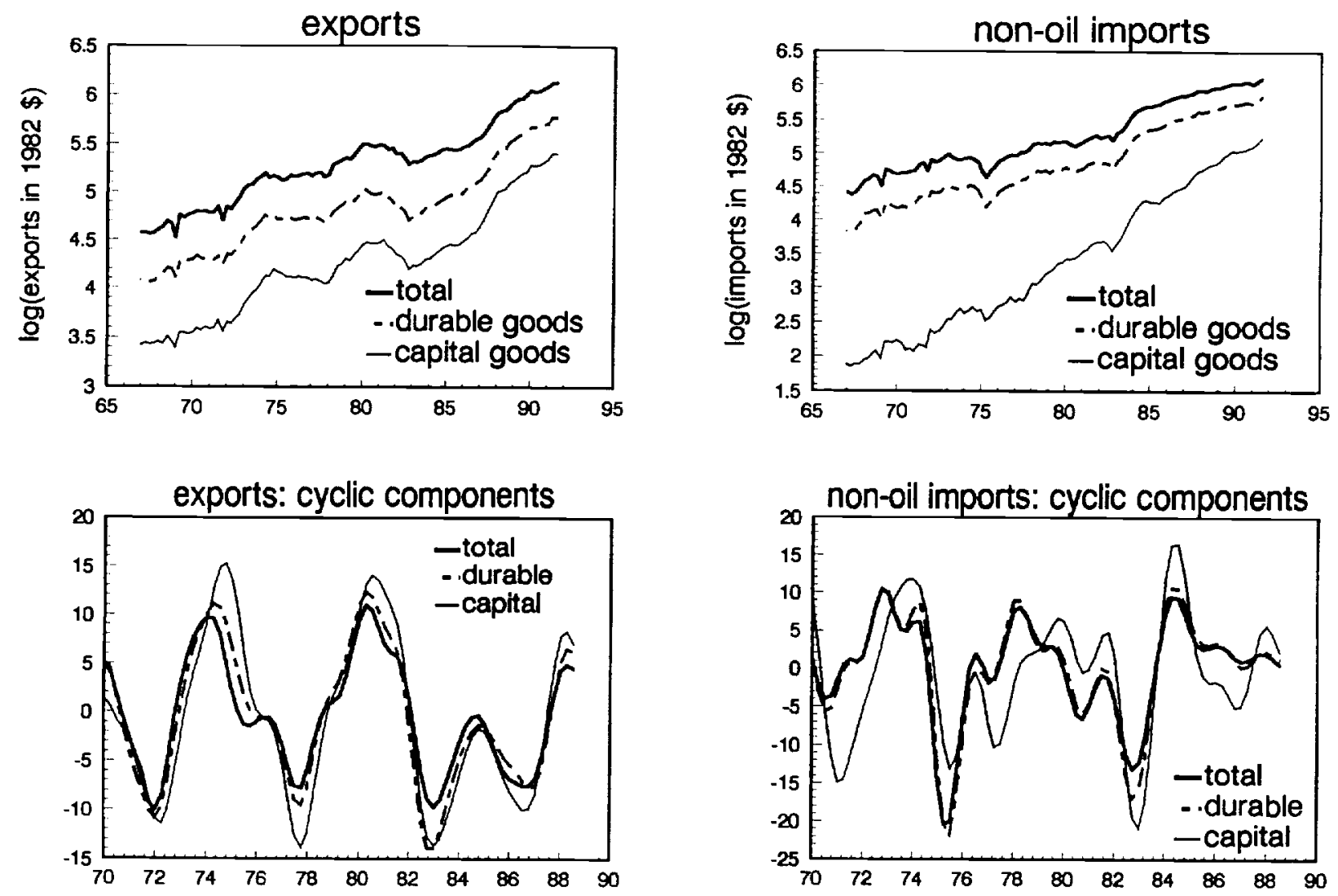
Figure 3: The Hicksian decomposition

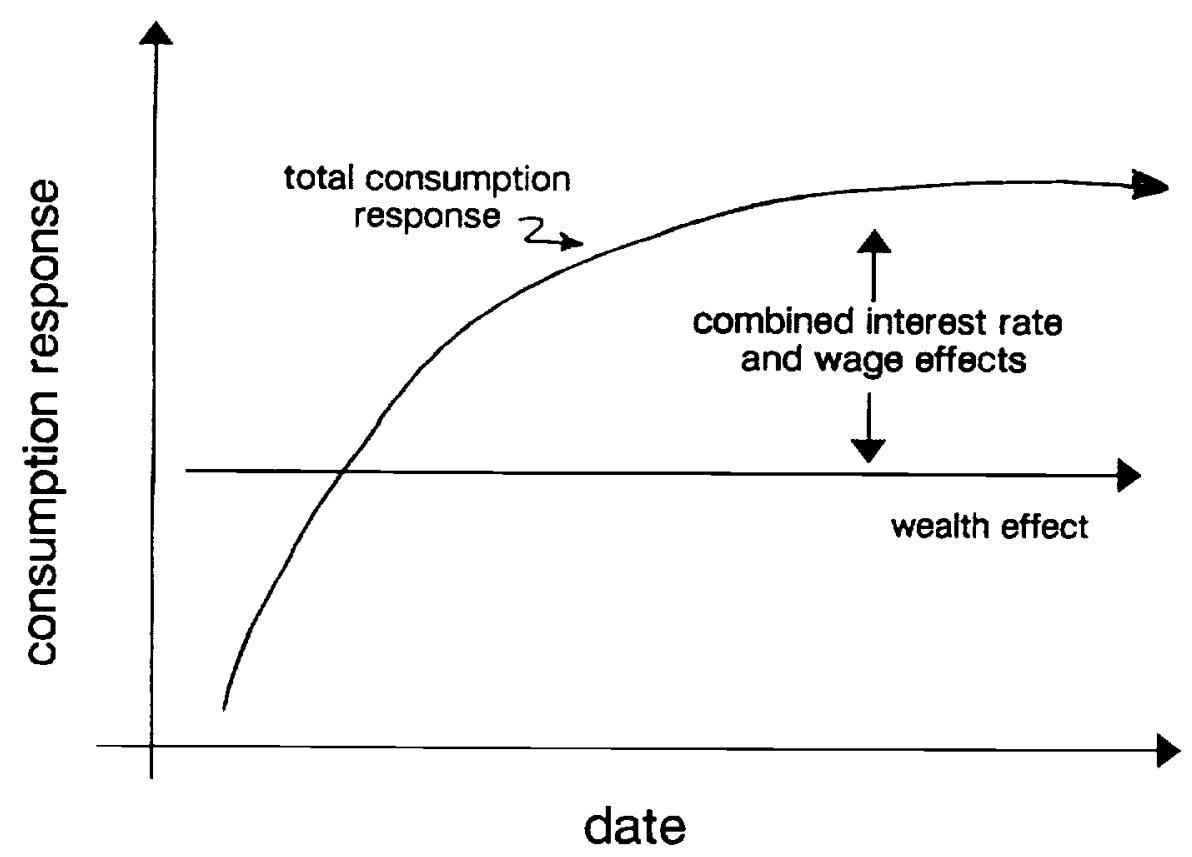


Figure 4: Permanent productivity shock in a small open economy with fixed labor input
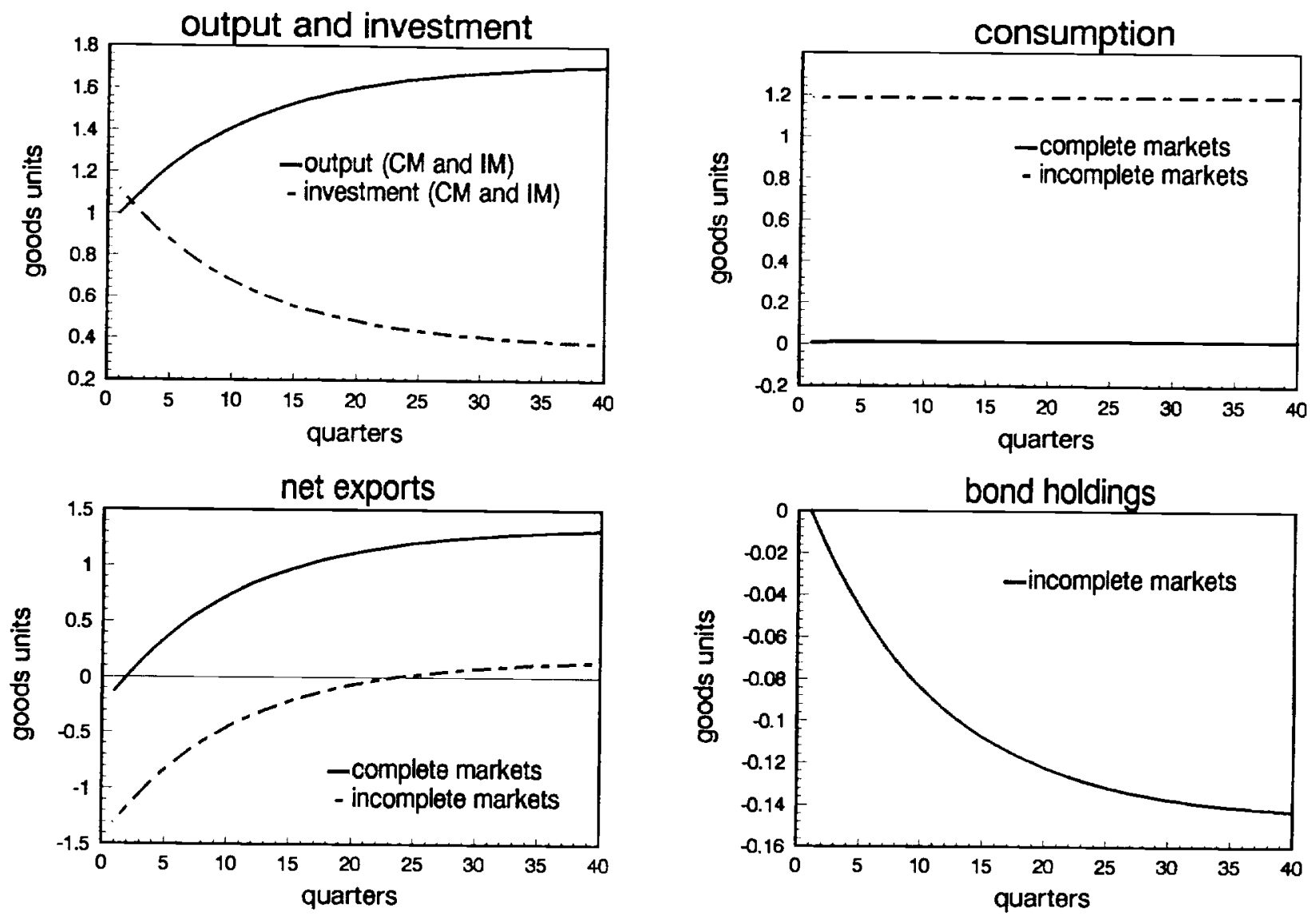
Figure 5-A: Permanent productivity shock in a small open economy with variable labor
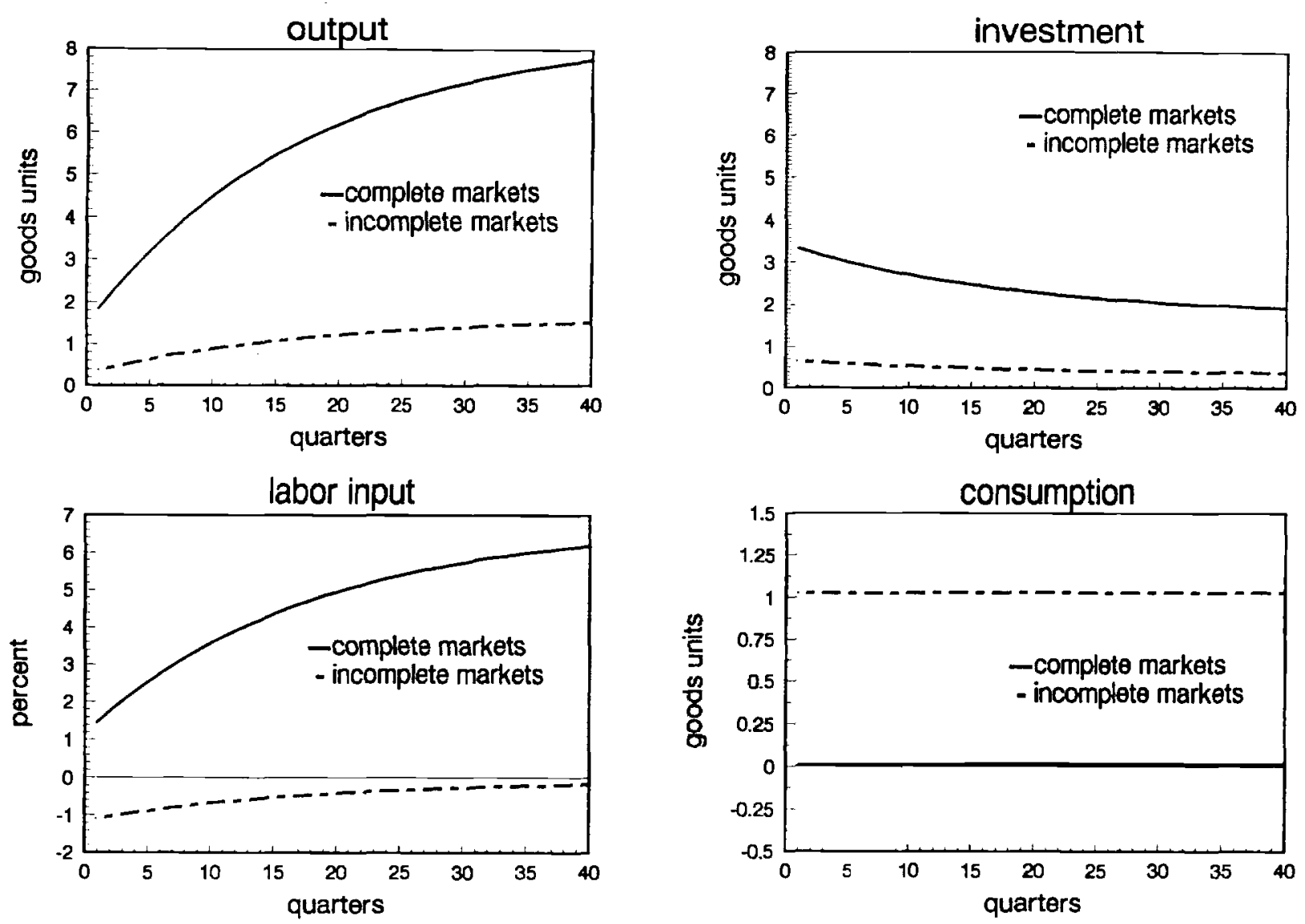
Figure 5-B

\section{Hicksian decomposition of consumption response}
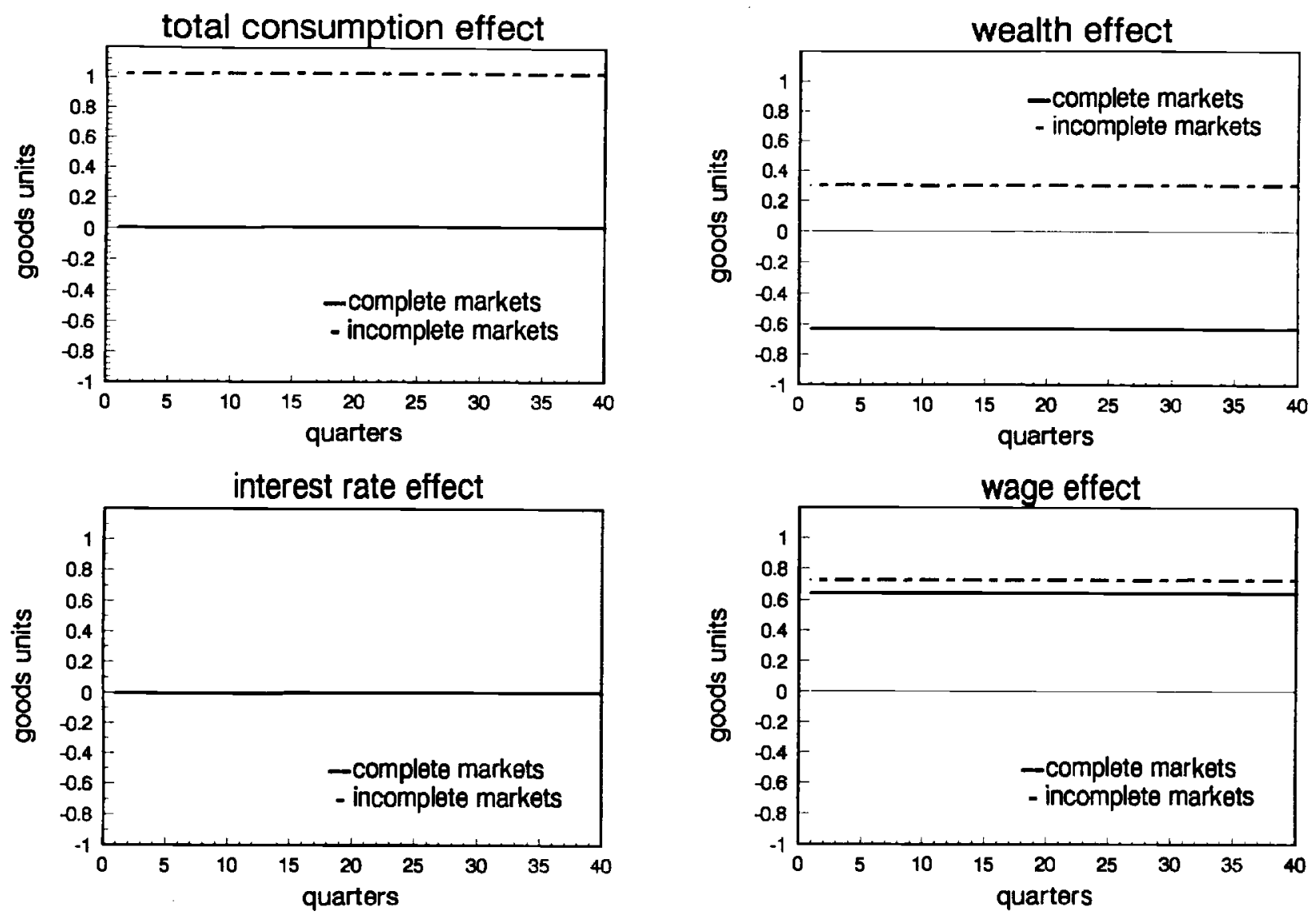

\section{Hicksian decomposition of labor response}
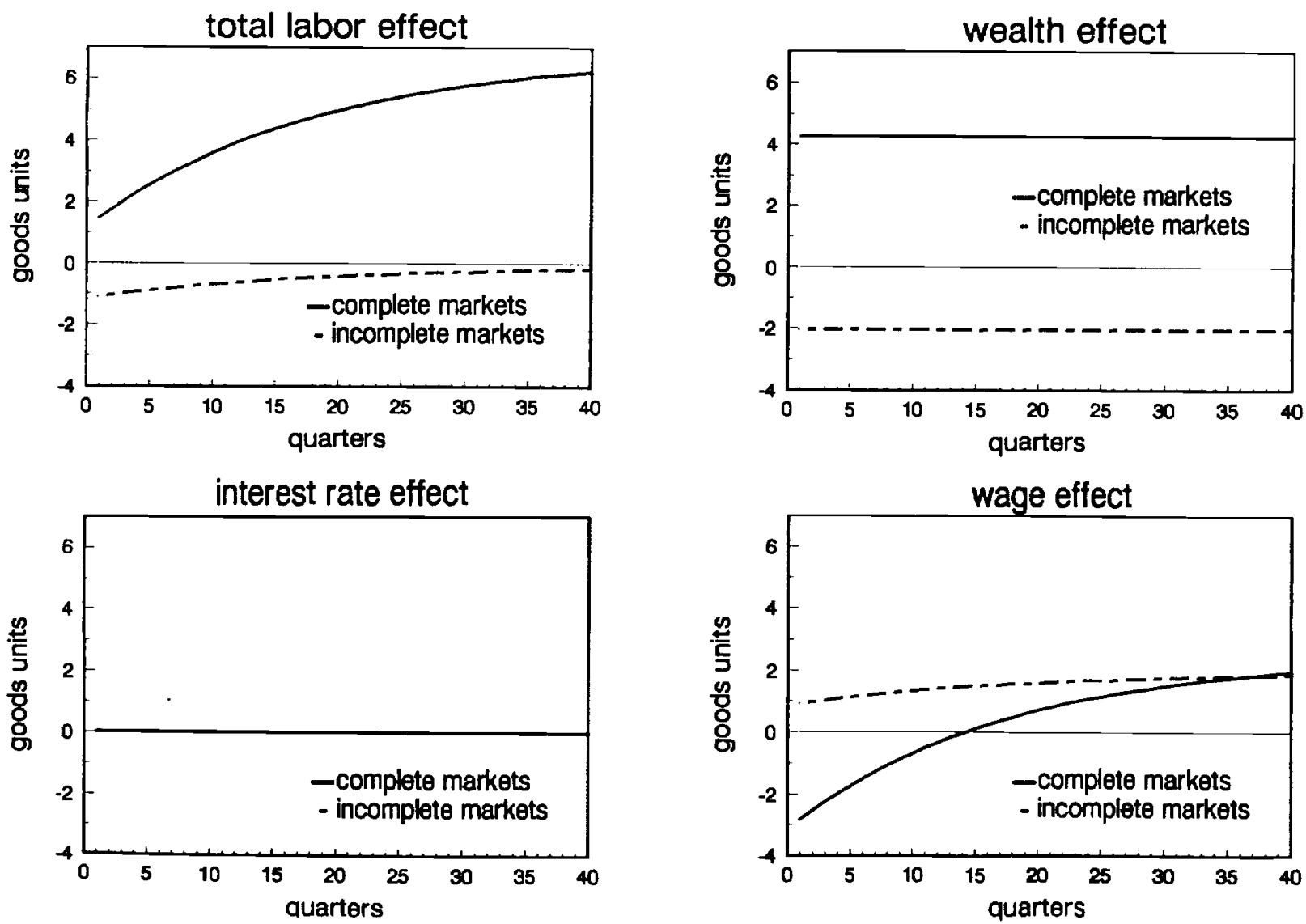
Figure 6-A: Permanent productivity shock in a large economy with variable labor
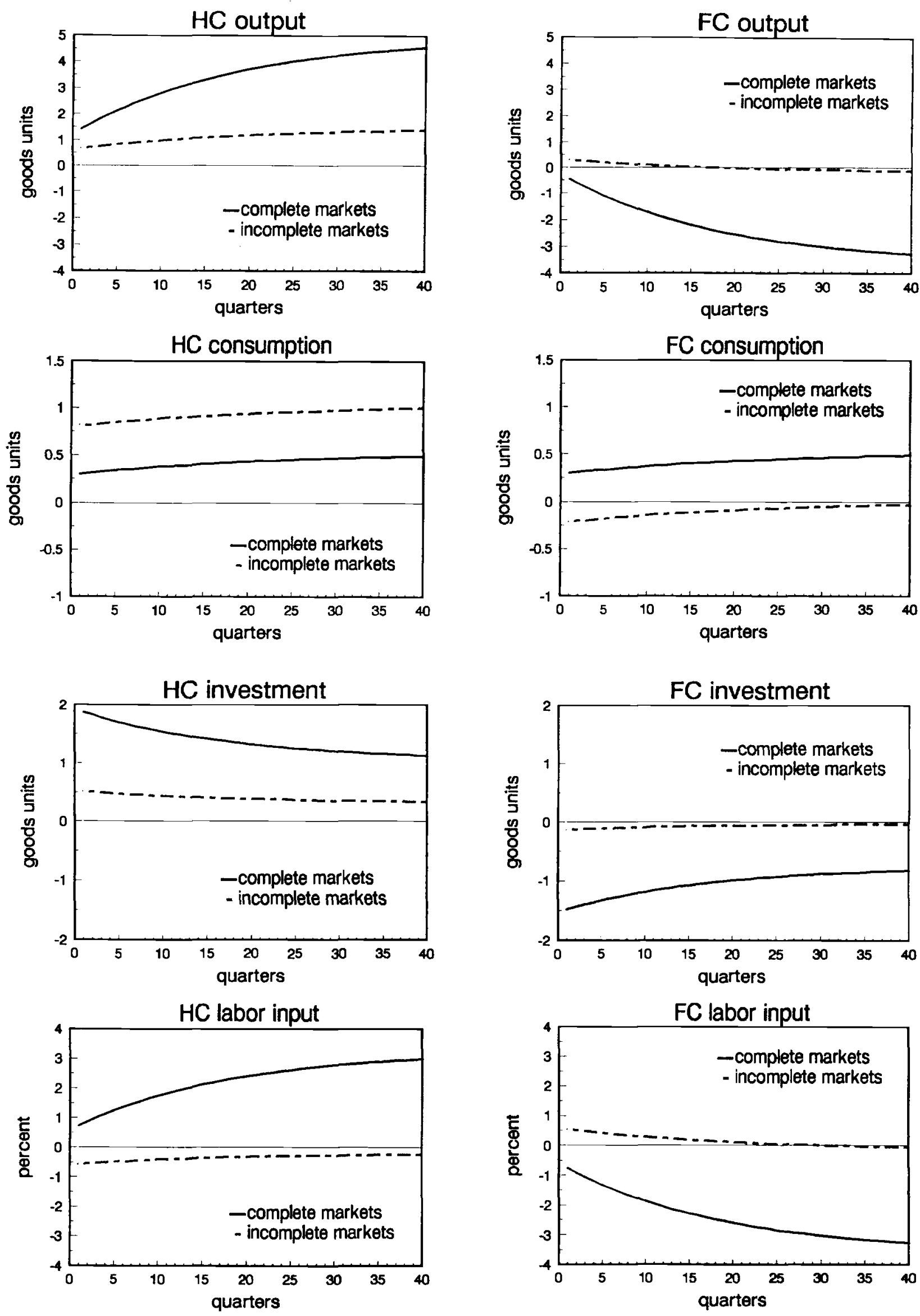
Figure 6-A, cont'd.
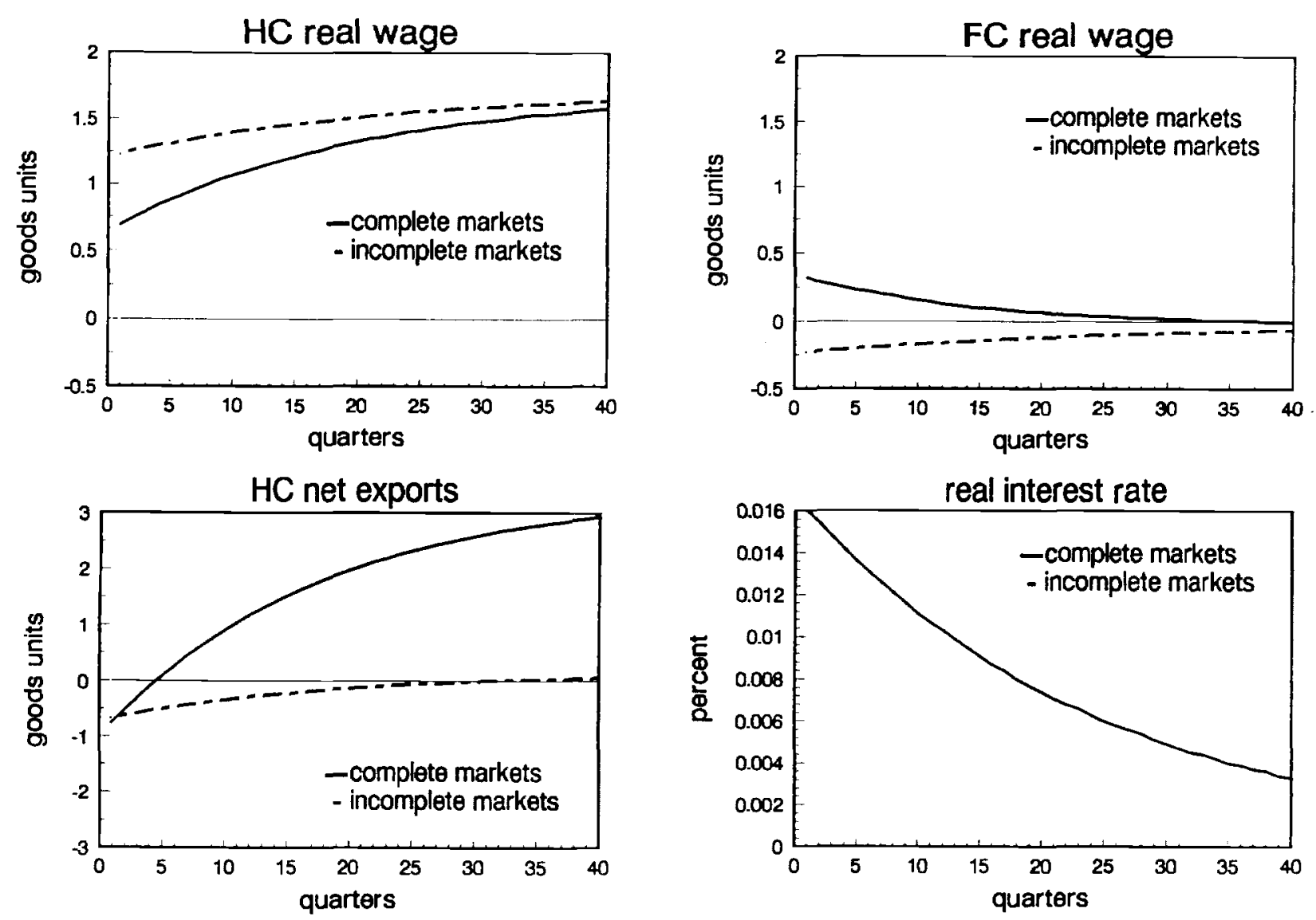
Figure 6-B

\section{Hicksian decomposition of consumption response}
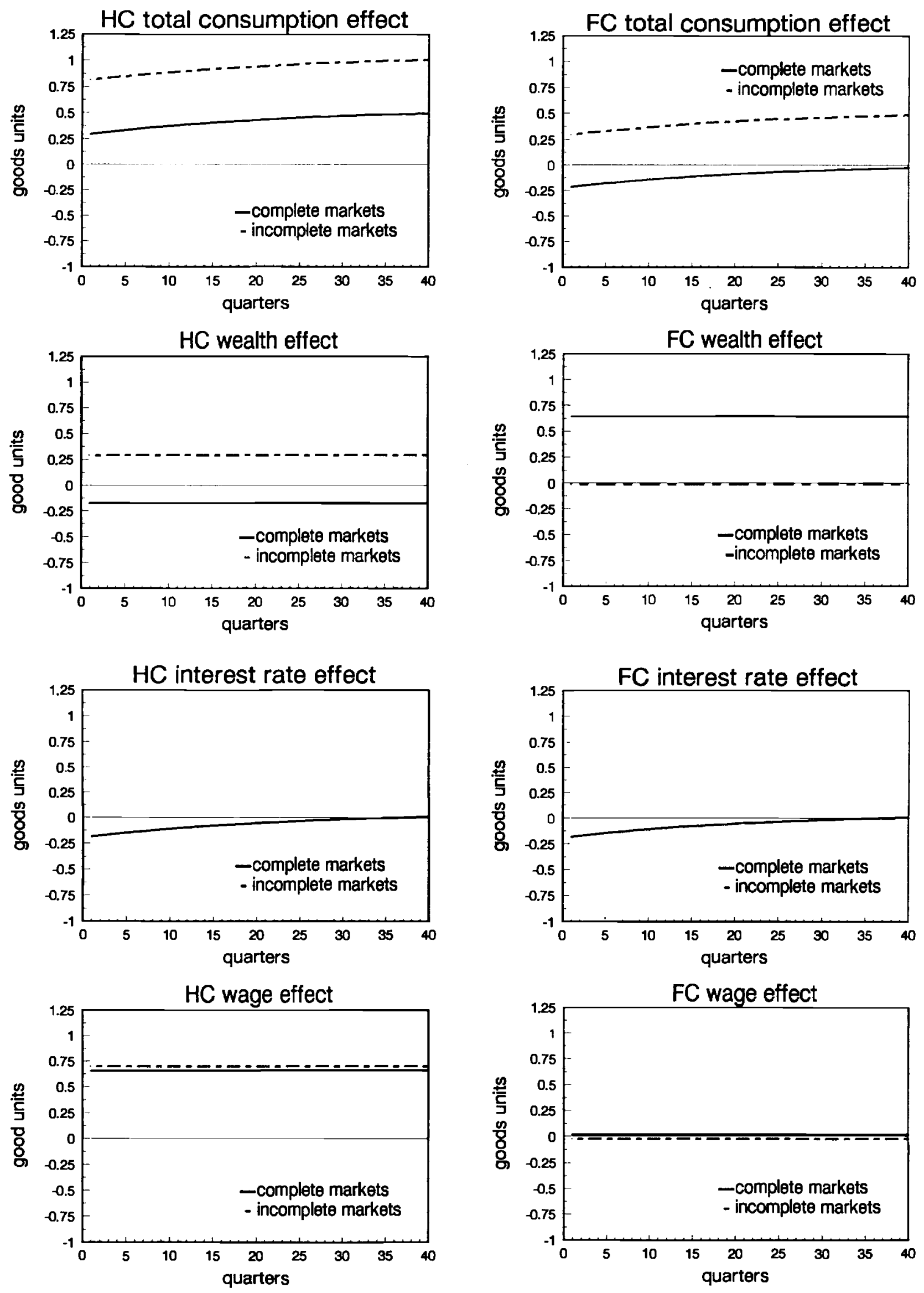
Figure 7: Trend stationary shocks with spillovers
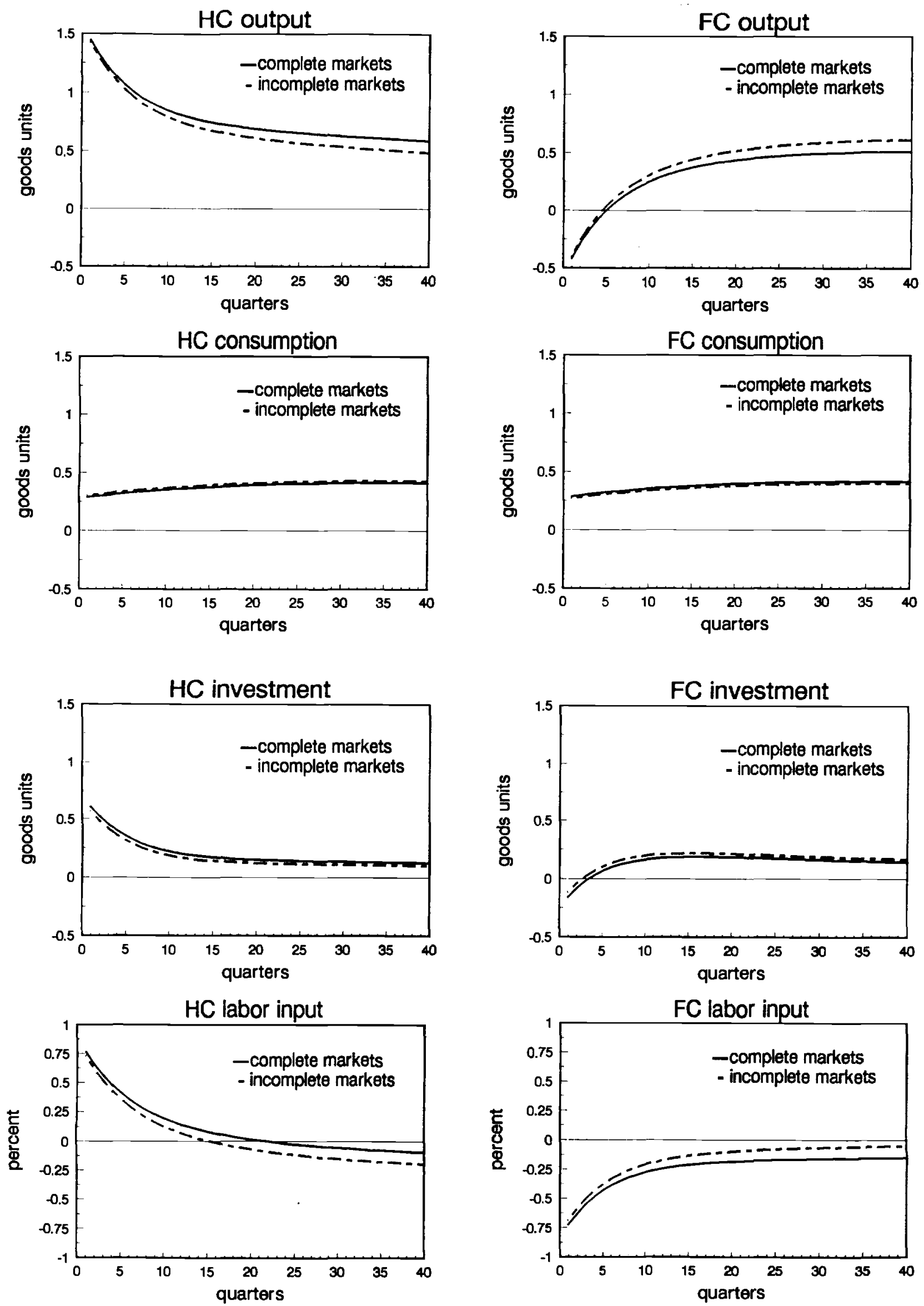
Figure 8: Permanent increase in government purchases: Incomplete markets case
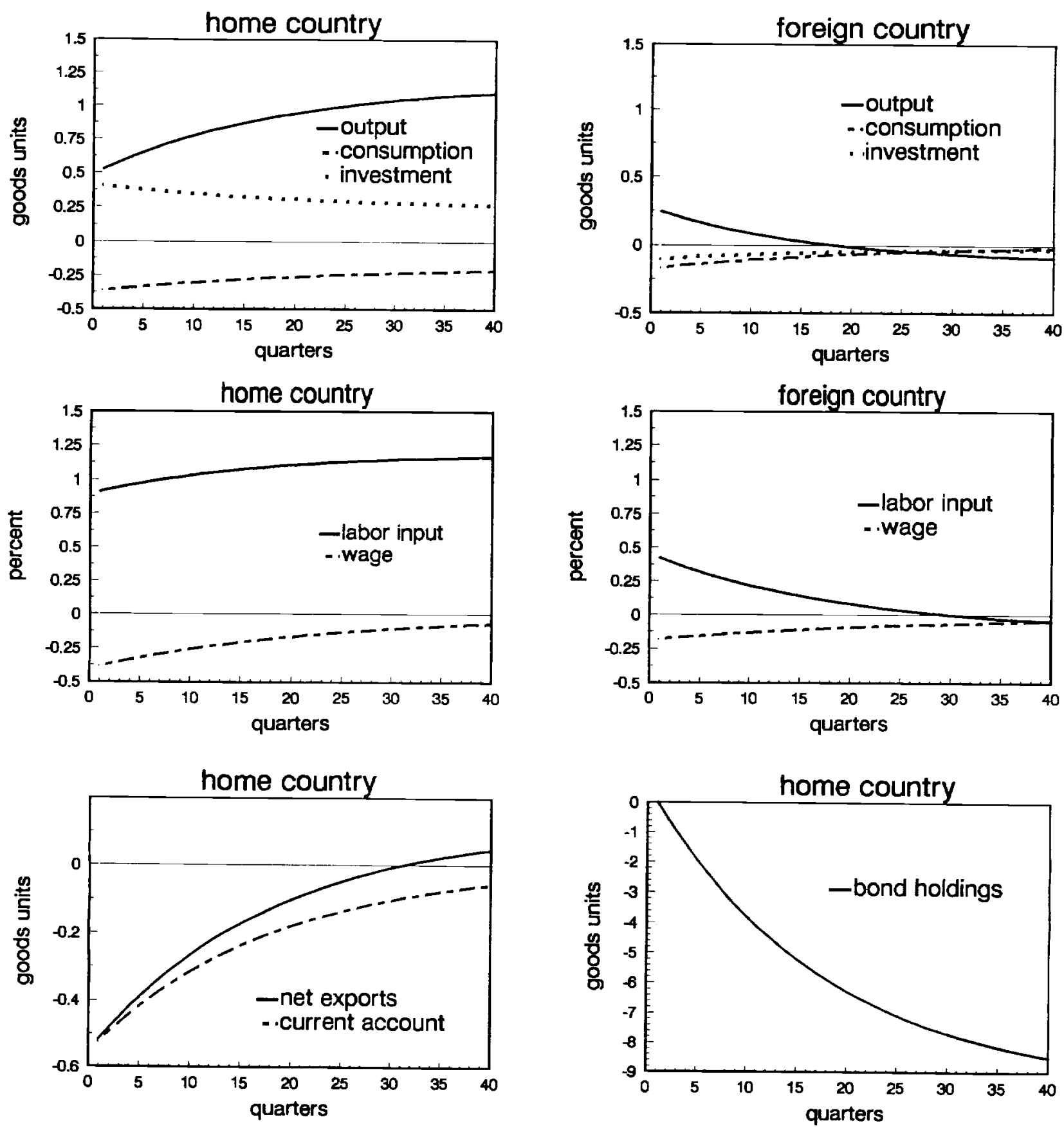
Figure 9: Permanent tax cut: incomplete markets case
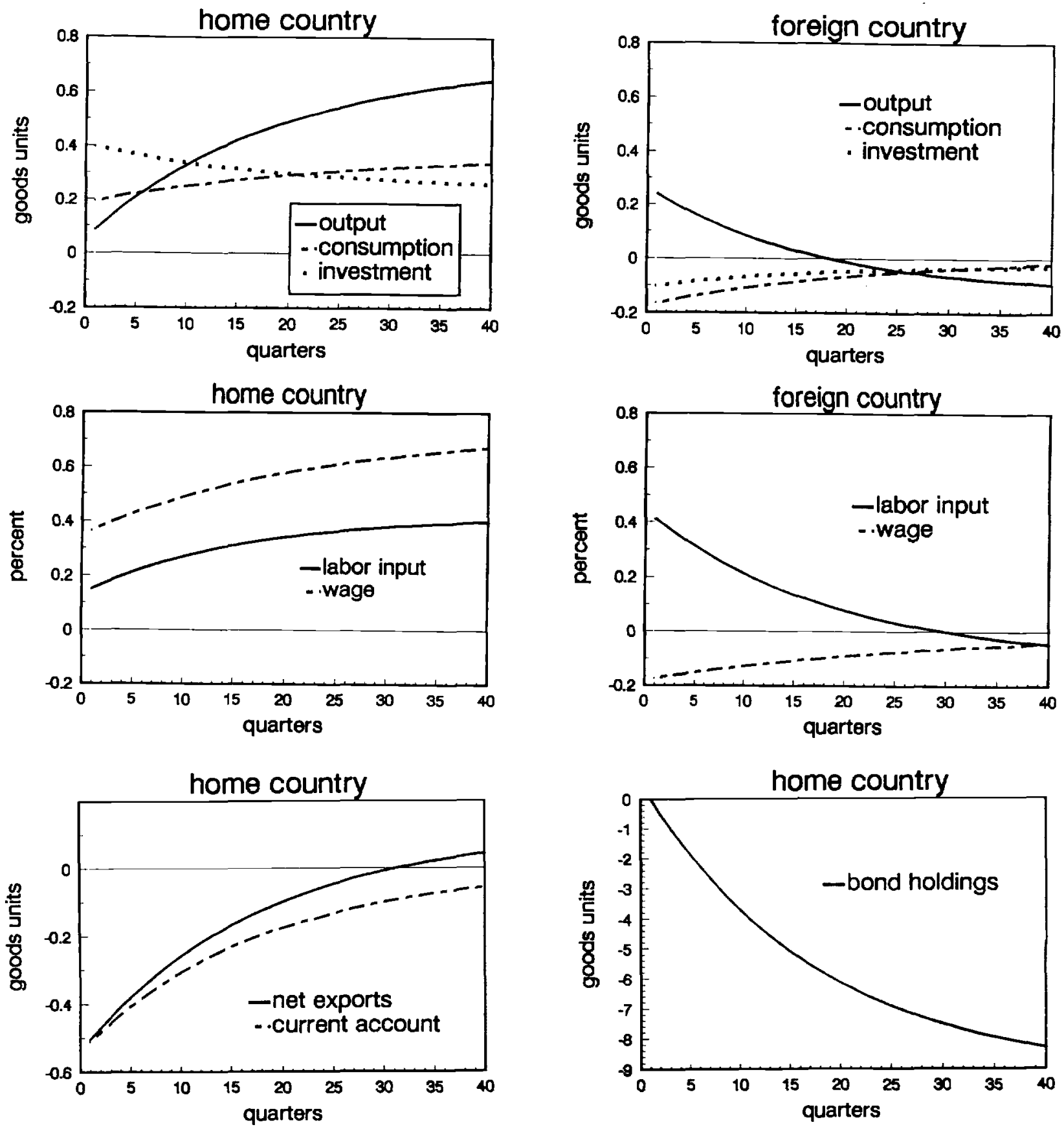
Figure 10: Cross-correlation between the terms of trade and net exports
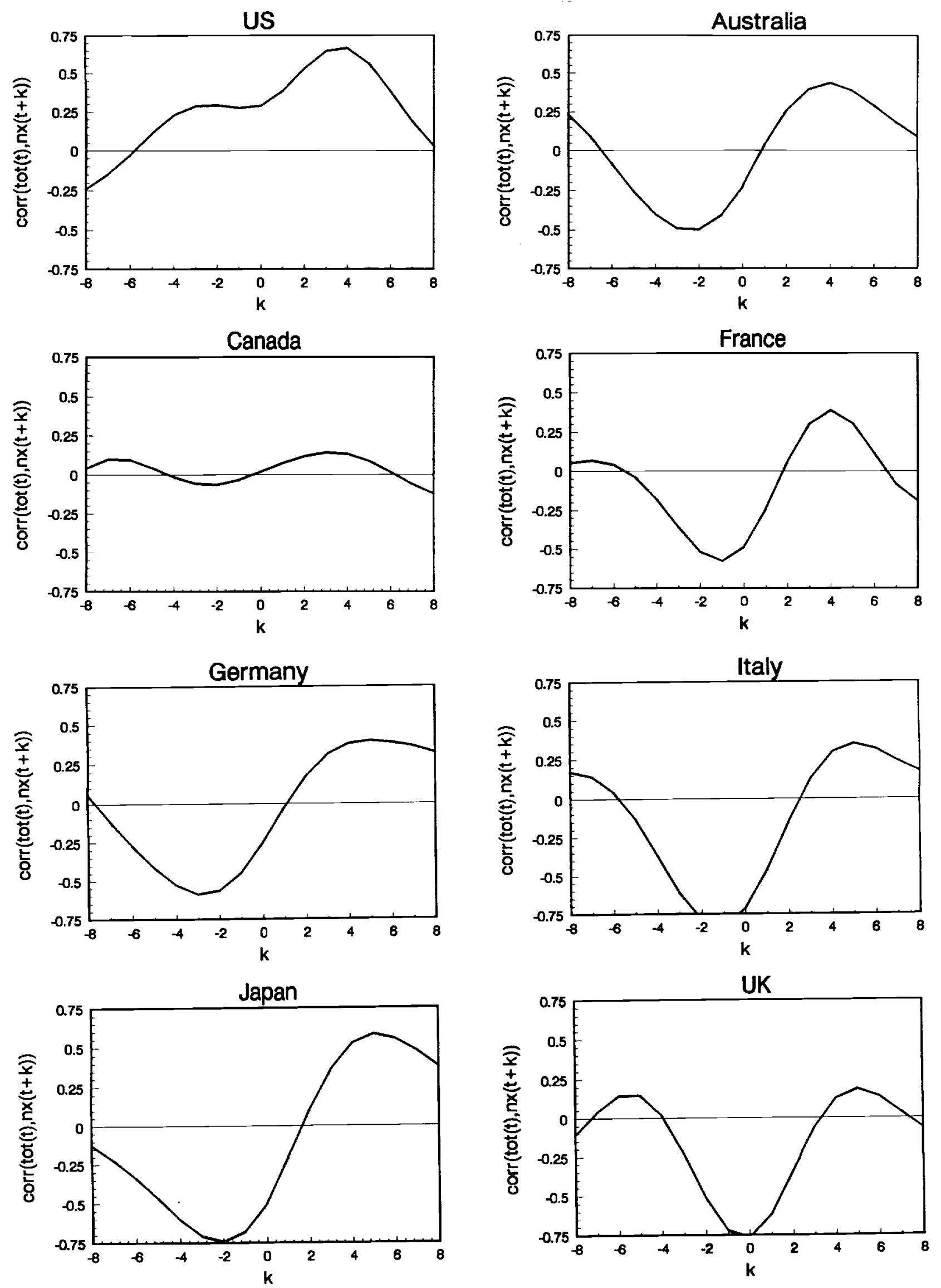